\title{
Inhibition of mitochondrial respiration prevents BRAF-mutant melanoma brain metastasis
}

Terje Sundstrøm 1,2,3, Lars Prestegarden 1,2,4, Francisco Azuaje, ${ }^{5,6}$, Synnøve Nymark Aasen 1,7, Gro Vatne Røsland ${ }^{8}$, Jobin K. Varughese ${ }^{1}$, Marzieh Bahador ${ }^{1}$, Simon Bernatz ${ }^{9}$, Yannick Braun ${ }^{9}$, Patrick N. Harter ${ }^{9}$, Kai Ove Skaftnesmo ${ }^{10}$, Elizabeth S. Ingham ${ }^{11}$, Lisa M. Mahakian ${ }^{11}$, Sarah Tam ${ }^{11}$, Clifford G. Tepper ${ }^{12}$, Kjell Petersen ${ }^{13}$, Katherine W. Ferrara ${ }^{11}$, Karl Johan Tronstad ${ }^{8}$, Morten Lund-Johansen ${ }^{2,3}$, Rudi Beschorner ${ }^{14}$, Rolf Bjerkvig ${ }^{1,5+}$ and Frits Thorsen ${ }^{1,15^{*}+}$

\begin{abstract}
Melanoma patients carry a high risk of developing brain metastases, and improvements in survival are still measured in weeks or months. Durable disease control within the brain is impeded by poor drug penetration across the blood-brain barrier, as well as intrinsic and acquired drug resistance. Augmented mitochondrial respiration is a key resistance mechanism in BRAF-mutant melanomas but, as we show in this study, this dependence on mitochondrial respiration may also be exploited therapeutically. We first used high-throughput pharmacogenomic profiling to identify potentially repurposable compounds against BRAF-mutant melanoma brain metastases. One of the compounds identified was $\beta$-sitosterol, a well-tolerated and brain-penetrable phytosterol. Here we show that $\beta$-sitosterol attenuates melanoma cell growth in vitro and also inhibits brain metastasis formation in vivo. Functional analyses indicated that the therapeutic potential of $\beta$-sitosterol was linked to mitochondrial interference. Mechanistically, $\beta$-sitosterol effectively reduced mitochondrial respiratory capacity, mediated by an inhibition of mitochondrial complex I. The net result of this action was increased oxidative stress that led to apoptosis. This effect was only seen in tumor cells, and not in normal cells. Large-scale analyses of human melanoma brain metastases indicated a significant role of mitochondrial complex I compared to brain metastases from other cancers. Finally, we observed completely abrogated BRAF inhibitor resistance when vemurafenib was combined with either $\beta$-sitosterol or a functional knockdown of mitochondrial complex I. In conclusion, based on its favorable tolerability, excellent brain bioavailability, and capacity to inhibit mitochondrial respiration, $\beta$-sitosterol represents a promising adjuvant to BRAF inhibitor therapy in patients with, or at risk for, melanoma brain metastases.
\end{abstract}

Keywords: Cancer, Melanoma, Brain metastasis, BRAF V600E, $\beta$-Sitosterol, Treatment

\section{Introduction}

Melanoma incidence rates are increasing, and brain metastases represent a leading cause of melanoma-associated deaths $[10,14,17,48]$. Even though phase II clinical trials have shown promising therapeutic effects by

\footnotetext{
* Correspondence: frits.thorsen@uib.no

${ }^{\dagger}$ Rolf Bjerkvig and Frits Thorsen contributed equally to this work.

${ }^{1}$ Kristian Gerhard Jebsen Brain Tumour Research Centre, Department of

Biomedicine, University of Bergen, Jonas Lies vei 91, 5009 Bergen, Norway

${ }^{15}$ The Molecular Imaging Center, Department of Biomedicine, University of

Bergen, Jonas Lies vei 91, 5009 Bergen, Norway

Full list of author information is available at the end of the article
}

the use of BRAF inhibitors (BRAFi) + MEK inhibitors (MEKi), resistance still develops [18, 32]. Also, in experimental studies it has been shown that immunotherapy combining anti-PD1 plus CTLA4 may have a therapeutic effect [59]. However, a major problem is the presence of the blood-brain barrier (BBB), which is intact during early stages of brain metastasis development [51]. Although the presence of metastases can compromise the structure and integrity of the $\mathrm{BBB}$, it is still a significant obstacle for efficient drug delivery [22, 31, 37, 66]. Moreover, cancer cells that have extravasated to the brain parenchyma may find protection within the brain

(c) The Author(s). 2019 Open Access This article is distributed under the terms of the Creative Commons Attribution 4.0 International License (http://creativecommons.org/licenses/by/4.0/), which permits unrestricted use, distribution, and 
microenvironment, and be more prone to develop resistance due to sub-therapeutic drug concentrations $[46,52]$. There are also significant concerns associated with drug-related adverse effects, patient selection, and costs versus benefits [56, 67]. Thus, there is a prevailing need to find new therapeutic and preventive approaches that offer improved and sustained responses against brain metastases [3, 52].

Recently, it has been shown that molecular drivers of cellular metabolic reprogramming events may be critical in tumor development, metastasis formation and drug resistance [1]. For instance, subsets of melanomas that show primary resistance to targeted therapies seem to rely more on mitochondrial respiration than glycolysis $[45,63]$. Furthermore, when $B R A F$-mutant melanomas are treated with vemurafenib (a BRAFi), the MITF-PGC1 $\alpha$ axis is up-regulated, which leads to increased mitochondrial respiration and scavenging of reactive oxygen species (ROS) [24]. These intrinsic and acquired resistance mechanisms provide obvious survival advantages, but the dependence on mitochondrial respiration may also be exploited therapeutically [24, 45, 49, 63, 69].

The metabolic alterations that occur in melanoma brain metastases are largely unknown, but cell lines derived from metastatic melanomas and melanoma metastases (non-brain) have shown elevated levels of mitochondrial respiration when compared to primary melanomas $[7,26]$. In the brain, metastatic breast cancer cells have been shown to be less dependent on glucose, and instead utilize mitochondrial respiration for energy production and antioxidant defense $[15,16]$. Moreover, metastatic breast cancer cells have been shown to display neuron-like characteristics in the brain microenvironment [39, 41]. Whether these changes reflect intrinsic or adaptive capabilities of tumor cells to thrive in the neural niche remains to be determined. Nevertheless, to survive and grow, extravasated cancer cells can adjust to the lower glucose levels in the brain interstitium [16]. Notably, when cancer cells are deprived of glucose they switch from glycolysis to mitochondrial respiration and become sensitive to low doses of mitochondrial complex I (CI) inhibitors that do not affect normal (non-cancerous) cells [40].

In this study (scientific flowchart outlined in Additional file 1: Figure S1), using a well-established patient derived metastatic xenograft model, we identified a melanoma brain metastasis gene signature by RNA-sequencing (RNA-seq). We then utilized the Connectivity Map drug discovery tool (cMap; Broad Institute) to search for putative therapeutic compounds with the potential to invert the signature. The lead compounds identified were then tested in predictive xenograft models of $B R A F$-mutant melanoma brain metastases. Here, we show that $\beta$-sitosterol, a well-tolerated and brain-penetrable phytosterol, effectively prevented the emergence of brain metastases leading to a significant survival benefit. Mechanistically, we show that $\beta$-sitosterol targets mitochondrial $\mathrm{CI}$ that leads to an inhibition of mitochondrial respiration. We also show that $\beta$-sitosterol abrogates potential resistance to $\mathrm{BRAFi}$, inferring a clear therapeutic rationale for using $\beta$-sitosterol as a therapeutic agent towards melanoma metastases.

\section{Materials and methods}

\section{Cell lines}

The H1 cell line was generated from a human melanoma brain metastasis and transduced with lentiviral vectors expressing the genes for GFP and luciferase (H1_DL2) as previously described [60], or shRNAs targeting NDUFA8 (H1_shNDUFA8; TAGAAGACGCACCGGCGGTGTTTA GGGGAAGGTAAAGTTAATATTCATAGCTTTGCCTT CCTCTAAACACCGTTTTTTGGCAAGCAAAAGACGG CATACGAGATATGTACCAGTCAGTACCAGTTTCGC

CGTCTTCGT). The Melmet 1 and Melmet 5 melanoma cell lines were developed from a skin and a lymph node metastasis, respectively, and were kindly provided by $\varnothing$. Fodstad (University of Oslo, Oslo, Norway). The A375 cell line was purchased from the American Type Culture Collection (ATCC). A human lung fibroblast cell line, SV-80, was purchased from CLS Cell Lines Service GmbH. The PC14-PE6 cell line was kindly provided by F. Winkler (University Hospital Heidelberg \& German Cancer Research Center, Heidelberg, Germany), and a brain seeking subline PC14_PE6_Br2 was generated in our laboratory as described earlier [27]. The Melmet 1 and Melmet 5 cell lines were transduced with a lentiviral pGF1-CMV reporter vector that co-expresses copGFP and firefly luciferase linked by the self-cleaving peptide T2A (System Biosciences). The immortalized human melanocytes-hTERT (cat. no. T0463) and astrocytes (cat.no. T0281) were both purchased from Applied Biological Materials (Richmond, BC, Canada). The primary epidermal melanocytes HEMa (cat.no. PCS-200-013) were purchased from ATCC. The H1, Melmet 1, Melmet 5 and A375 cell lines have the $B R A F^{V 600 E}$ mutation. The transduced cell lines were used in all experiments, authenticated within the last six months using short tandem repeat (STR) profiling, and maintained as previously described [57].

\section{In vivo generation of samples for RNA sequencing}

Eight weeks old female NOD.CB17-Prkdc $c^{\text {scid }} / \mathrm{NcrCrl}$ mice were purchased from Charles River Laboratories International. Anesthesia was induced with $3 \%$ and maintained with $1.5 \%$ isofluorane in oxygen. We performed intracardiac injections in seven mice $\left(5 \times 10^{5}\right.$ H1_DL2 cells suspended in $0.1 \mathrm{~mL}$ PBS) as previously described [60]. Whole-body bioluminescence imaging (BLI) was used to evaluate injection failure $10 \mathrm{~min}$ post-injection and weekly over seven weeks to monitor 
metastasis formation (Additional file 2: Figure S2a) using a Xenogen Ivis 100 Small Animal Molecular Imager (Xenogen Corporation) as previously described [60]. At seven weeks, we injected $150 \mathrm{mg} / \mathrm{kg}$ D-luciferin Firefly (Gold Biotechnology), sacrificed the mice ten min later, and performed ex vivo BLI to evaluate organ involvement in detail. All animals invariably developed metastases in their brain, adrenals, ovaries, and femurs, and these organs from five animals showing the highest tumor burden on BLI, were dissociated using tailored protocols based on the Liberase TM Research Grade enzyme reagent (Roche Applied Science; Additional file 3 Table S1). Sample yields of GFP positive tumor cells were checked by fluorescence microscopy prior to cell sorting (Additional file 2: Figure S2b) using the BD Influx high-speed cell sorter (BD Biosciences). We aimed for a minimum of 150,000 cells in each sample, and picked the three tumor cell samples from each organ with the most cells for subsequent RNA sequencing: 1) brain (151,023, 150,835 and 154,797 cells); 2) adrenals (151,968, 184,506 and 276,146 cells); 3 ) ovaries $(159,736$, 171,814 and 433,703 cells); and 4) femurs (120,530, 91,055 and 73,942 cells). These 12 samples (3 samples $\times$ 4 organs) of metastatic melanoma cells were kept in $1 \%$ FBS medium, pelleted by centrifugation, transported on dry ice and stored in a $-80^{\circ} \mathrm{C}$ freezer.

\section{RNA isolation}

Total cellular RNA was isolated from the cell pellets using the TRIzol reagent (Life Technologies) and a modified protocol that incorporates an additional extraction with phenol/chloroform/isoamyl alcohol (25:24:1, pH 4.3). RNA quantity and quality were assessed on a NanoDrop spectrophotometer (Thermo Scientific) and the Agilent 2100 Bioanalyzer (Agilent Technologies), respectively.

\section{Library preparation for RNA sequencing}

RNA sequencing (RNA-Seq) libraries were prepared from $1.0 \mu \mathrm{g}$ total RNA using the TruSeq RNA Sample Preparation Kit (Illumina) according to the manufacturer's protocol. Briefly, poly-adenylated mRNA was purified from total RNA and ribosomal RNA removed by two rounds of binding to magnetic poly-dT beads. This was followed by RNA fragmentation by incubation in the presence of divalent cations at $94{ }^{\circ} \mathrm{C}$ for $5 \mathrm{~min}$. Double-stranded cDNA was then generated by randomprimed first-strand synthesis with SuperScript II reverse transcriptase and subsequent second strand synthesis with RNase $\mathrm{H}$ and DNA Polymerase I. The cDNA was then blunt-ended with T4 and Klenow DNA polymerases to remove the $3^{\prime}$-overhangs and fill in $5^{\prime}$-overhangs, phosphorylated with T4 PNK, and then 3 '-A tailed by incubation with Klenow Fragment $\left(3^{\prime} \rightarrow 5^{\prime}\right.$ exo-) and dATP. Illumina paired-end (PE) adapters were then ligated, followed by purification with AMPure XP beads. The library was then enriched by high-fidelity PCR amplification ( 15 cycles) with Phusion DNA Polymerase (Finnzymes Oy) and adapter-specific primers. The molar concentration of the libraries was determined by measuring concentration with a Qubit fluorometer (Invitrogen), determining the insert length with an Agilent 2100 Bioanalyzer, and then qPCR-based quantification (KAPA Library Quantification Kit).

\section{RNA sequencing}

Indexed libraries were pooled, loaded on TruSeq pairedend flow cells, and paired-end sequencing $(2 \times 100 \mathrm{bp}$, paired-end; 4 libraries/lane) was performed with an Illumina HiSeq 2000 sequencing system (BGI@UC Davis Joint Genome Center) using standard Illumina kitted reagents (TruSeq SBS Kit v3-HS). Image processing, base calling, quality scoring (Phred), and sample demultiplexing were executed by HiSeq Control Software with Real Time Analysis (HCS 1.5/RTA 1.13) and CASAVA 1.8 software (Illumina). The Tuxedo protocol (http:// compbio.mit.edu/cummeRbund) was followed using the alternate protocol of quantification of reference annotation only. We used Ensembl's human genome build 19, and supplied TopHat with a set of known transcripts from Ensembl. The three BAM files from each individual organ were merged using Picard 1.91 (http://broadinstitute.github.io/picard), and these merged files were subsequently visualized using Integrative Genomics Viewer 2.3 (http://www.broadinstitute.org/igv). The cummeRbund package (http://compbio.mit.edu/cummeRbund) and Partek Genomics Suite 6.12 (Partek Inc.) were used to produce visualizations (Additional file 2: Figure S2c).

\section{Gene expression analysis and brain metastasis gene signature}

We developed an integrated workflow of several independent analyses to build a brain metastasis gene expression profile (Fig. 1b and Additional file 2: Figure S2d). First, there were 134 genes differentially expressed in brain metastases and metastases to any of the other organs; 122 genes were upregulated and 54 were downregulated in brain (some genes appeared in multiple lists). Second, we used Prediction Analysis for Microarrays (PAM; http:// statweb.stanford.edu/ tibs/PAM) to identify which of the 134 genes consistently distinguished brain metastases from other organ metastases. We found ten upregulated genes specific to brain metastases. Third, we validated eight of these ten genes using a combination of other computational analyses: A supervised rank product analysis (RankProd; http://www.bioconductor.org/packages/release/bioc/html/RankProd.html) of brain metastases compared with all the other organs pooled together 

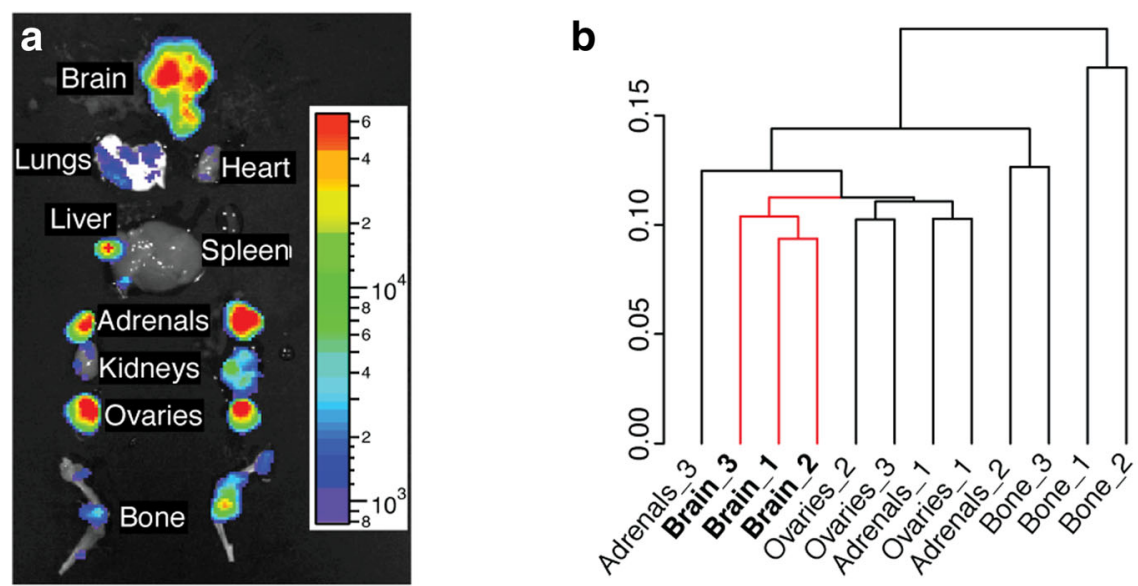

C

Compounds with potential to invert the brain metastasis gene signature

\begin{tabular}{lllll}
\hline Name & CAS & Dose $(\mu \mathrm{M})$ & cMap score & MW $(\mathrm{g} / \mathrm{mol})$ \\
\hline Meticrane & $1084-65-7$ & 15 & -1 & 275.34 \\
Tolazamide & $1156-19-0$ & 13 & -0.989 & 311.4 \\
$\beta$-sitosterol & $83-46-5$ & 10 & -0.984 & 414.7 \\
Memantine & $41100-52-1$ & 19 & -0.971 & 215.77 \\
Niridazole & $61-57-4$ & 19 & -0.967 & 214.22 \\
Valproic acid & $1069-66-5$ & 200 & -0.966 & 166.2 \\
Letrozole & $112809-51-5$ & 14 & -0.965 & 285.31 \\
Todralazine & $3778-76-5$ & 15 & -0.96 & 268.7 \\
Thiostrepton & $1393-48-2$ & 2 & -0.932 & 1664.8 \\
Levocabastine & $79547-78-7$ & 9 & -0.927 & 456.98 \\
\hline
\end{tabular}

Fig. 1 Prediction of candidate compounds from inverse gene profiling. a Detailed mapping of organ involvement by ex vivo BLI of a representative NOD.CB17-Prkdc scid/NcrCrl mouse seven weeks after intracardial injection of $5 \times 10^{5} \mathrm{H} 1$ _DL2 cells $(n=7)$. $\mathbf{b}$ Dendrogram of all replicates $(n=3$ per organ) based upon cluster analysis of gene expression profiles. Numbers 1,2 and 3 indicate sample ID. c Top ten compounds from the Connectivity Map (cMap) analysis with the potential to induce the opposite transcriptional response to the brain metastasis signature («anti-brain metastasis signature»). Chemical abstracts service (CAS) registry numbers, reported dose tested, cMap score and molecular weight ( $M_{W}$ ) are provided. A cMap score of -1 indicates complete reversal of the signature (negative correlation)

( $\mathrm{pfp}<0.01)$; a meta-analysis of rank product analyses (RankProd) of brain metastases versus each of the other organs ( $\mathrm{pfp}<0.01)$; and significance analysis of microarrays (http://statweb.stanford.edu/ tibs/SAM) with a q-value cutoff of 0.05 . Fourth, we performed hierarchical clustering using J-Express 2012 (http://jexpress. bioinfo.no/site) and identified 46 genes that clustered together with the cross-validated eight-gene list; these 54 up-regulated genes were used to build a brain metastasis gene signature. Fifth, to enable analysis with the Connectivity Map (cMap) database, we appended the 54 most downregulated genes from the supervised rank product analysis (RankProd) of brain metastases when compared with all the other organs pooled together; all of these 54 downregulated genes were also featured in the 134-gene list of differentially expressed genes, as described above. Thus, the 108-gene brain metastasis signature was comprised of 54 upregulated and 54 downregulated genes (Additional file 2: Figure S2d).

\section{Computational prediction of candidate compounds}

We queried the cMap build 2 database (http://www. broadinstitute.org/cmap) using our 108-gene signature for candidate drugs. cMap is an initiative by the Broad Institute of MIT and Harvard, where the effects of 1309 small molecules on a number of cultured human cells were examined systematically, resulting in a collection of more than 7000 expression profiles that can be freely queried using their web interface. This resource can be used to select for drugs that produce a disease-negating gene signature. In this study, cMap was hypothesized to predict drugs with the potential to induce opposite expression profiles to those observed in our brain metastasis gene signature (Additional file 2: Figure S2e). Before cMap analysis, gene symbols were mapped to HG-U133A probe IDs (microarray used in cMap). The HG-U133A probe file (Platform GPL96) was downloaded and mapping was done with a code written in our laboratory. Of the 54 upregulated genes, 37 genes 
had at least one matching probe and 55 probes were retrieved in total. Of the 54 downregulated genes, 29 genes had at least one matching probe, and 40 probes were retrieved in total. Mappings were subsequently verified with the GeneAnnot (http://genecards.weizmann.ac. il/geneannot/index.shtml) and GeneCards (http://www. genecards.org) databases.

\section{Candidate drugs}

Nine drugs were purchased from Santa Cruz Biotechnology, Inc.: Meticrane, tolazamide, $\beta$-sitosterol, memantine hydrochloride (herein referred to as memantine), valproic acid, letrozole, todralazine, thiostrepton, and levocabastine. Niridazole was not available. For in vitro screening, all compounds were dissolved in $100 \%$ dimethyl sulfoxide (DMSO) to a stock concentration of $250 \mathrm{mM}$. All stock solutions were subsequently diluted in complete DMEM to nine working solutions ranging from 0.2 to $1312.3 \mu \mathrm{M}$. This dose spectrum covered well below and above the reported dose levels for all drugs described in cMap. PLX4720 (ChemieTek) was solubilized and diluted in a similar manner to nine working solutions ranging from
0.01 to $1562.5 \mu \mathrm{M}$. Prior to in vitro testing, we pre-warmed $\left(37^{\circ} \mathrm{C}\right)$ and sonicated all working solutions.

\section{Proliferation assays}

Cells from four BRAF mutated cell lines (H1_DL2, Melmet 1, Melmet 5, A375) and three normal cell lines (SV80; fibroblasts, hTERT melanocytes and human astrocytes) were quantified using a hemocytometer and seeded into 96-well plates (5000 cells per well) in $100 \mu \mathrm{L}$ complete DMEM. After $24 \mathrm{~h}$ incubation, we added $100 \mu \mathrm{L}$ of the nine graded candidate drug dilutions, PLX4720, or $100 \mu \mathrm{L} 0.1 \%$ or $1.0 \%$ DMSO in complete DMEM to each well ( $n=18$ per cell line per drug per drug concentration). Three days later, we added $20 \mu \mathrm{L}$ of resazurin $0.1 \mathrm{mg} / \mathrm{mL}$ (Sigma-Aldrich Co.) per well and read the plates $4 \mathrm{~h}$ later (Fig. 2a and Additional file 4: Figure S3a-f) using a VICTOR X3 multilabel plate reader (PerkinElmer) with Workout 2.5 data analysis software $(560 \mathrm{~nm}$ excitation and $590 \mathrm{~nm}$ emission). Wells with $200 \mu \mathrm{L}$ complete DMEM and no cells were used for background correction $(n=60) . \mathrm{IC}_{50}$ values were calculated (Fig. 2c, and Additional file 4: Figure S3) using GraphPad Prism 6 for Mac OS X (GraphPad Software Inc.).

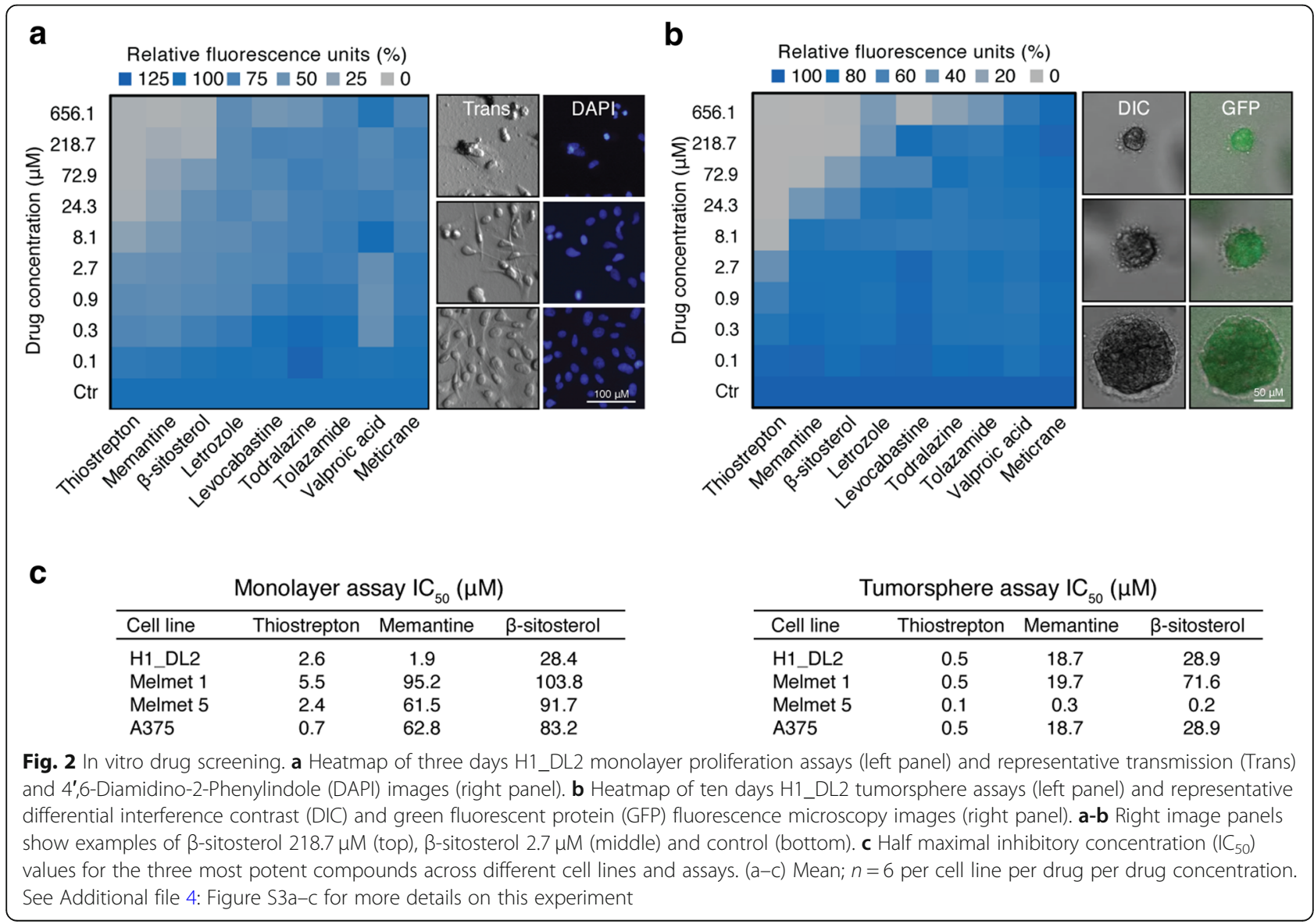


Cells were fixed by adding $50 \mu \mathrm{L} 8 \%$ paraformaldehyde (PFA) per well for $24 \mathrm{~h}$ after which time the liquid contents of all wells were replaced with $50 \mu \mathrm{L}$ PBS. Differential interference contrast (DIC) and 4',6-diamidino-2-phenylindole (DAPI) image stacks were acquired (Fig. 2a) with 10× magnification using a Nikon Eclipse TE2000 inverted microscope (Nikon Instruments Inc.).

\section{Tumorsphere assay}

A standardized 3D tumor spheroid growth assay was carried out as reported previously [58]. Briefly, $100 \mu \mathrm{L}$ of the graded drug dilutions and DMSO controls were added to 96-well plates with 4000 cells in soft agar per well ( $n=6$ per cell line per drug concentration). After a ten-day incubation period, a resazurin assay was performed, and cells were fixed as described above. DIC and GFP z-stack images were acquired with $10 \times$ magnification using a BD Pathway 855 High-Content Imager (Becton, Dickinson and Company).

\section{Tumor cell injections, quantification of tumor cell load in the brain and multimodal imaging of metastasis formation}

Six to eight weeks old female NOD/SCID mice were purchased from the University of Bergen animal facility. Anesthesia was induced with $3 \%$ and maintained with $1.5 \%$ isoflurane in oxygen. Mice were monitored daily and sacrificed upon signs of illness. Intracardiac injections were performed using ultrasound-guidance $\left(5 \times 10^{5}\right.$ cells per $0.1 \mathrm{~mL}$ PBS per mouse) as reported previously [58]. H1_DL2 cells were pre-labeled with superparamagnetic iron oxide nanoparticles and MRI was carried out $24 \mathrm{~h}$ after injections [57]; T2*-weighted images for automated quantification of tumor cell load in the mouse brains and T2-weighted images to assess the presence of focal brain lesions. MRI equipment and sequence details have previously been described [58]. For T2\%-weighted quantification we developed a cell-line specific training set for the integrated neural network analysis. Only mice with comparable tumor cell load in their brains and without ischemic lesions were included in further studies. We omitted five mice in the candidate drug study and six mice in the $\beta$-sitosterol study, based on an uneven tumor load to the brain.

We performed brain MRI to evaluate the brain metastatic burden with T2-weighted sequences and pre -/post-contrast T1-weighted sequences as previously described [58]. Images were obtained at pre-defined week numbers (Figs. 3a, b and $4 \mathrm{a}, \mathrm{b}$ ). The number of tumors, contrast enhancement and volume $\left(4 / 3 \times \pi \times r^{3}\right)$ were assessed using OsiriX 5.8.1 32-bit (Pixmeo SARL).

In parallel with the MRI, we did BLI to evaluate brain metastatic burden. Mice were imaged $10 \mathrm{~min}$ after i.p. injection of $150 \mathrm{mg} / \mathrm{kg}$ D-luciferin Firefly (Gold
Biotechnology). To reduce distress, they were not depilated. Images were acquired using an Optix MX3 Small Animal Molecular Imager (ART Inc.) and analyzed with Optix OptiView 3.02 (ART Inc.). Total photon counts (ventral + dorsal) were registered from identically sized regions of interest (ROIs) placed over the head.

\section{In vivo treatment protocols}

In the drug screening study on H1_DL2 brain metastases, treatment started one week post-injection and stopped at the end of week seven (Fig. 3a and Additional file 5: Figure S4). Test groups received $0.2 \mathrm{~mL}$ i.p. injections of $40 \mathrm{mg} / \mathrm{kg}$ thiostrepton every second day $(n=5)$, $10 \mathrm{mg} / \mathrm{kg}$ memantine daily $(\mathrm{n}=5), 5 \mathrm{mg} / \mathrm{kg} \beta$-sitosterol daily $(n=4)$, or $0.5 \%$ DMSO $(n=5)$ daily. Stock solutions of the respective drugs, as described above, were diluted with saline solution, pre-warmed $\left(37^{\circ} \mathrm{C}\right)$ and sonicated prior to i.p. injections (the partly miscible thiostrepton solution was homogenized before administration). Fresh solutions were made every second week and stored at $4{ }^{\circ} \mathrm{C}$.

In the validation study with $\beta$-sitosterol treatment on H1_DL2 cells and PC14_PE6_Br2 brain metastases, treatment started one week prior to intracardiac injections and was continued until sacrifice for the vehicle groups $(n=10)$ and for ten weeks for the $\beta$-sitosterol groups $(n=9)$. Test groups received daily i.p. injections of 0.1 $\mathrm{mL}$ olive oil or $5 \mathrm{mg} / \mathrm{kg} \beta$-sitosterol in $0.1 \mathrm{~mL}$ olive oil. $\beta$-sitosterol was mixed with olive oil (Santa Cruz Biotechnology Inc) and solubilized over $4 \mathrm{~h}$ with a heated magnetic stirrer $\left(50{ }^{\circ} \mathrm{C}\right)$. Fresh solutions were made every second week and stored at room temperature.

In the subcutaneous tumor model, we used the Melmet 5 melanoma cell line. We injected $1 \times 10^{6}$ cells in $0.1 \mathrm{~mL}$ PBS in the cervical skin fold of 32 mice. After two weeks, when the average tumor volume was approximately $30 \mathrm{~mm}^{3}$, the mice were randomized to daily i.p. injections of $0.1 \mathrm{~mL}$ vehicle (olive oil), $20 \mathrm{mg} / \mathrm{kg} \beta$-sitosterol in olive oil, $25 \mathrm{mg} / \mathrm{kg}$ PLX4720 in 0.05\% DMSO, or a combination of the two latter ( $n=8$ in each group). Caliper measurements were carried out every sixth day to evaluate tumor growth. Tumor volume was calculated using the formula (width ${ }^{2} \times$ length) $/ 2$.

\section{Functional classification of the brain metastasis gene signature}

We performed a functional classification of human biological processes and signaling pathways associated with the 108-gene signature using the Protein Analysis Through Evolutionary Relationships (PANTHER) classification system (http://www.pantherdb.org/).

\section{Protein interactions of $\beta$-sitosterol}

We examined known and predicted protein interactions of $\beta$-sitosterol using the Search Tool for Interactions of 


\section{a}

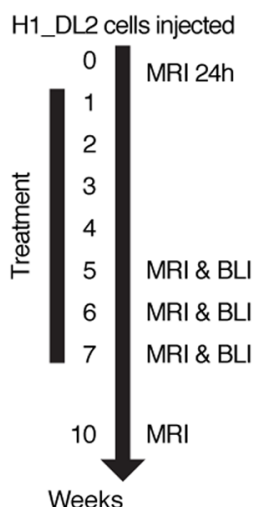

C

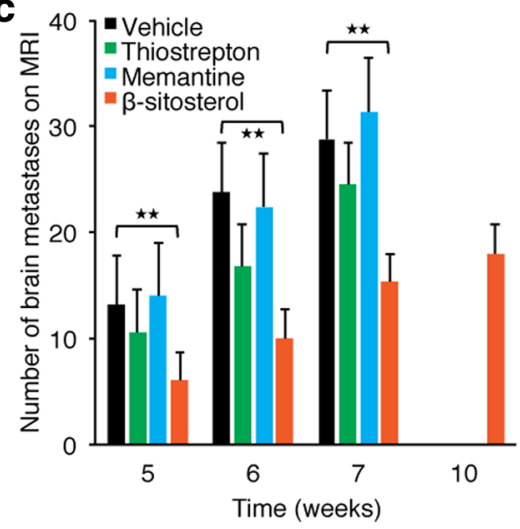

b

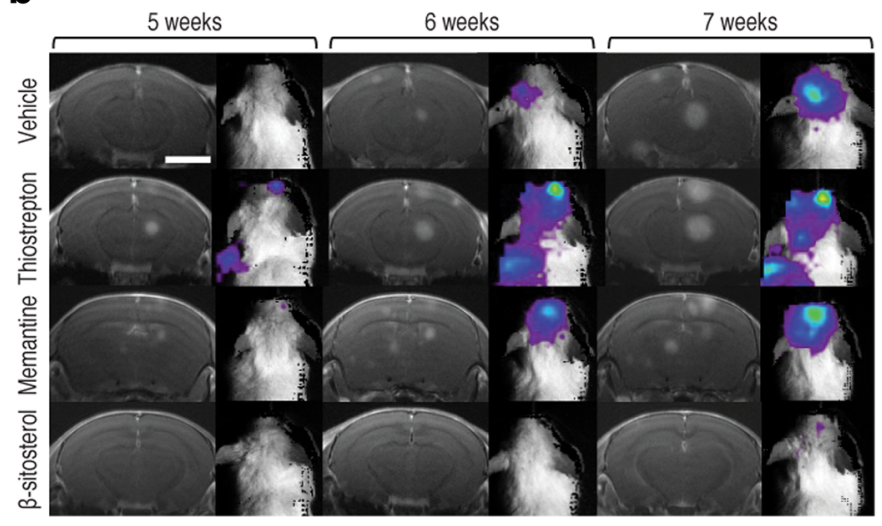

d

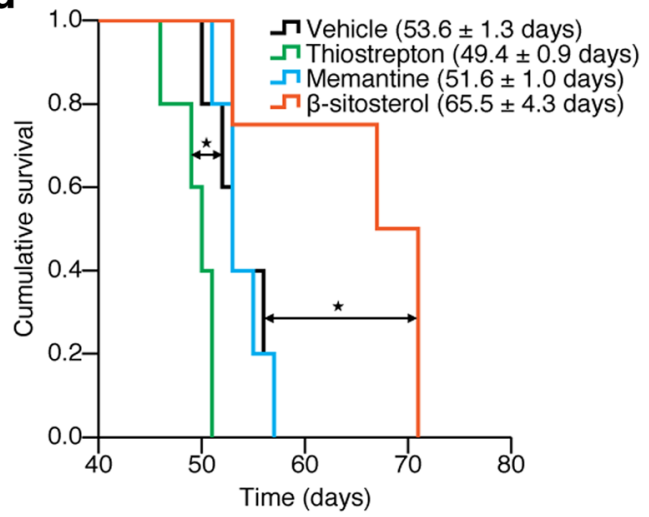

Fig. 3 In vivo drug screening. a Experimental overview: Intracardiac injections of $5 \times 10^{5} \mathrm{H} 1$ _DL2 cells in NOD/SCID mice were followed by MRIbased quantification of nanoparticle-labeled melanoma cells in the mouse brains after $24 \mathrm{~h}$ for group homogenization (Additional file 5: Figure S4a). Treatment started after one week, and test groups received $0.2 \mathrm{~mL}$ i.p. injections of $40 \mathrm{mg} / \mathrm{kg}$ thiostrepton every second day $(n=5), 10 \mathrm{mg} /$ $\mathrm{kg}$ memantine daily $(n=5), 5 \mathrm{mg} / \mathrm{kg} \beta$-sitosterol daily $(n=4)$ or vehicle $(0.5 \%$ DMSO; $\mathrm{n}=5)$. See Additional file 5 : Figure $S 4$ for more details. $\mathbf{b}$ Development of brain metastases visualized by MRI (T1-weighted images with contrast) and BLI at five, six and seven weeks. Scale bar MRIs, 0.25 cm. c Number of brain metastases at T1-weighted MRI with contrast (Student's t-test). d Kaplan-Meier survival plot (Mantel-Cox log-rank test). There was no significant difference between vehicle- and memantine-treated mice. ${ }^{*} P<0.05$; ${ }^{* *} P<0.01$. All values are given as the mean \pm s.e.m

Chemicals (STITCH 4.0; http://www.stitch.embl.de). We applied a high confidence level cut-off $(0.700)$ and a maximal number of interactions $(n=50)$. We next investigated with which cellular processes these protein targets were associated using the Human Experimental/ Functional Mapper (HEFalMp).

\section{Protein phosphorylation assay}

For the determination of the relative levels of protein phosphorylation of 43 kinases and 2 related total proteins (HSP60 and $\beta$-Catenin), we used the Human Phospho-Kinase Array (R\&D Systems, Inc.) as specified by the manufacturer. H1_DL2 cells were treated with vehicle $(0.05 \% \mathrm{DMSO})$ or $\beta$-sitosterol $(50 \mu \mathrm{M})$ for $24 \mathrm{~h}$.

\section{Linkage analyses to mitochondrial metabolism}

We obtained the mitochondrial metabolism genes from the Gene Ontology (GO) database using AmiGO (http://amigo.geneontology.org/amigo) and the search term «oxidative phosphorylation» (filter: Homo sapiens). This resulted in 121 unique gene symbols among a total of 209 gene-term associations. $\beta$-sitosterol targets were extracted from ChEMBL (Chemical Database of the European Molecular Biology Laboratory; https://www.ebi. ac.uk/chembl): 16 targets reported in humans. CHEMBL_IDs were converted to gene symbols with UnitProtKB (Universal Protein Resource Knowledgebase; http://www. uniprot.org). Network generation and visualization were implemented in Cytoscape 3.3.0 (http://www.cytoscape. org). Interactions between query and mitochondrial metabolism gene sets were extracted with ANAT (Advanced Network Analysis Tool; http://www.cs.tau.ac.il/ bnet/ ANAT). $\beta$-sitosterol targets and signature genes were defined as network anchors, and the oxidative phosphorylation genes as network terminals. Anchored network analysis was applied with focus on: human interactions, 


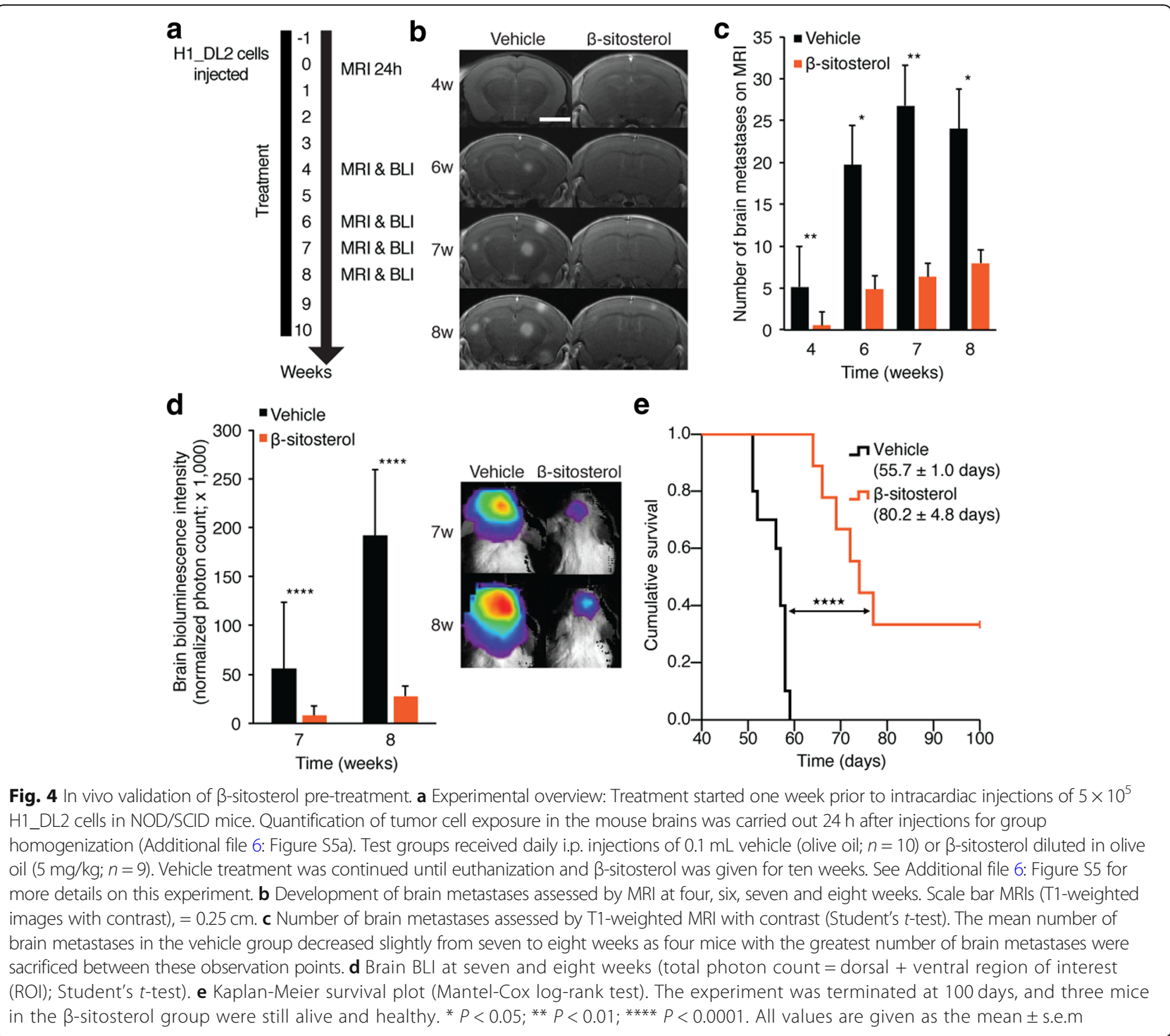

protein-protein and protein-DNA interactions and default search parameters. Interaction directionality from anchors to terminals was specified.

\section{Extracellular flux analysis}

Extracellular flux analysis with concurrent detection of oxygen (mitochondrial respiration) and $\mathrm{pH}$ (lactate production indicating glycolysis) was employed. The measurements were performed in 96-well H1_DL2 and HEMa cell cultures using the Seahorse XF96 Analyzer system (Seahorse Bioscience), according to manufacturer's protocol. The assay conditions were optimized with regard to cell number and concentrations of carbonyl cyanide 3-chlorophenylhydrazone (CCCP) or carbonyl cyanide-4 (trifluoromethoxy) phenylhydrazone (FCCP) and oligomycin. Cells were seeded in quadruplicate wells $\left(2 \times 10^{4}\right.$ cells per well), and exposed to $50 \mu \mathrm{M} \beta$-sitosterol for $24 \mathrm{~h}$ before the analysis. Control cells received $0.05 \%$ DMSO. Following this treatment, the growth medium was replaced with assay medium consisting of phenol-free DMEM supplemented with $2 \mathrm{mM}$ L-glutamine and $2 \mathrm{mM}$ sodium pyruvate. $10 \mathrm{mM}$ glucose was added to the medium for measurement of mitochondrial respiration. The assay medium was adjusted to a $\mathrm{pH}$ of 7.4. The cells were incubated at $37^{\circ} \mathrm{C}$ in a $\mathrm{CO}_{2}$-free incubator (Seahorse XF Prep station) for $1 \mathrm{~h}$ before they were transferred to the analyzer. To investigate mitochondrial respiratory function, assessment of the initial oxygen consumption rate (OCR), indicating the basal rate, was followed by sequential additions of several modulators: 1 ) the ATP synthase inhibitor oligomycin ( $3 \mu \mathrm{M}$ for H1_DL2 and $2 \mu \mathrm{M}$ for HEMa cells) was used to measure phosphorylation independent respiration (Leak); 2) the uncoupler CCCP or FCCP $(1.5$ or $2 \mu \mathrm{M}$ for H1_DL2 and HEMa cells, 
respectively) to measure the capacity of the electron transport system (respiratory capacity); 3) the Complex I (CI) inhibitor rotenone $(1 \mu \mathrm{M})$ to determine $\mathrm{CI}$ independent respiration; and 4) the CIII inhibitor antimycin A $(1 \mu \mathrm{M})$ to assess residual background OCR not related to mitochondrial respiration; this was subtracted as background from the other measurements in the statistical analysis. To analyze the glycolytic function, the extracellular acidification rate (ECAR) was measured after sequential additions of glucose $(10 \mathrm{mM})$ to determine basal glycolysis and oligomycin $(3 \mu \mathrm{M})$ to obtain glycolytic capacity. CCCP $(1.5 \mu \mathrm{M})$ was injected to address the possible influence of uncoupling, and 2-deoxyglucose (2-DG; $100 \mathrm{mM}$ ) was used to obtain the non-glycolytic background. In statistical analysis, the residual ECAR was subtracted as background from the other measurements. All experiments were performed three times.

\section{High-resolution respirometry}

Oxygen consumption was analyzed using the Oxygraph O2K instrument and DatLab software (Oroboros Instruments). The H1_DL2 cells were harvested and washed in PBS before they were suspended in the assay medium (20 mM K-hepes, $83 \mathrm{mM} \mathrm{KCl}, 4 \mathrm{mM}$ KH2PO4, $1 \mathrm{mM}$ EGTA and $1 \mathrm{mM} \mathrm{MgCl} 2$ ) and transferred to the assay chamber $\left(37^{\circ} \mathrm{C}\right)$ at $1.25 \times 10^{6}$ cells per $2 \mathrm{~mL}$ assay medium. Digitonin $(8.1 \mu \mathrm{M})$ was added to permabilize the cell membrane. The combined $\mathrm{CI}+\mathrm{CII}$-driven respiration was obtained in the presence of malate $(2 \mathrm{mM})$, pyruvate $(1 \mathrm{mM})$, succinate $(10$ $\mathrm{mM}$ ), and FCCP (titrated to $0.18 \mu \mathrm{M}$ ). Following injection of $\beta$-sitosterol $(50 \mu \mathrm{M})$ or DMSO $(0.05 \%)$ and assessment of the resulting OCRs, rotenone $(0.5 \mu \mathrm{M})$ was injected to determine if the effect was linked to $\mathrm{CI}$ and/or CII. Antimycin A $(2.3 \mu \mathrm{M})$ was added to provide the non-mitochondrial background activity, which was subtracted during data analysis. This experiment was performed three times.

\section{Measurement of reactive oxygen species and apoptosis assay} H1_DL2 cells were treated with $0.05 \%$ DMSO or $50 \mu \mathrm{M}$ $\beta$-sitosterol for $24 \mathrm{~h}$, and apoptosis was detected and quantified using the disodium salt of $3,4,5,6$,-tetrachloro-2', 4', 5', 7'-tetraiodofluorescein (TCTF) as previously described $(n=3)$ [34]. The cellular content of reactive oxygen species (ROS) was measured using the CM- $\mathrm{H}_{2}$ DCFDA probe according to the manufacturer's instructions (Life Technologies). Briefly, naïve $\mathrm{H} 1$ cells were treated with $0.05 \%$ DMSO or $50 \mu \mathrm{M} \beta$-sitosterol for $2 \mathrm{~h}$ before exposure to $5 \mu \mathrm{M}$ CM- $\mathrm{H}_{2}$ DCFDA for 15 min (two experiments with triplicate measurements). Data were analyzed using a BD Accuri C6 flow cytometer (BD Biosciences).

\section{Western blot}

Protein extraction and western blotting was carried out as described previously [58]. Antibodies were diluted in blocking buffer and the following antibodies were used: Caspase-3 (1:500) and PGC1 $\alpha$ (1:500) (Cell Signaling Technology); and NDUFA8 (ab74126; 1:500), GAPDH $(1: 20,000)$ and $\beta$-actin $(1: 20,000)$ (Abcam).

\section{MitoTracker red fluorescence}

MitoTracker Red (Invitrogen) mean fluorescence intensity was measured in $\mathrm{H} 1$ cells treated with DMSO $(0.05 \%)$ or PLX4720 $(1.5 \mu \mathrm{M})$ for $72 \mathrm{~h}(\mathrm{n}=3)$. Data were analyzed using a BD Accuri C6 flow cytometer (BD Biosciences).

\section{Colony formation assay}

$5 \times 10^{3} \mathrm{H} 1$ cells were cultured in 6-well plates and treated with DMSO (0.05\%), PLX4720 (1.5 $\mu \mathrm{M})$, $\beta$-sitosterol $(50 \mu \mathrm{M})$, or a combination of the latter two for one (controls) or three weeks (treatment groups) $(\mathrm{n}=3)$. The same protocol was used for H1_shNDUFA8 cells, but these were not treated with $\beta$-sitosterol.

\section{Immunohistochemistry of human brain metastases}

We stained 197 formalin-fixed and paraffin-embedded human brain metastases using NDUFB8 (ab110242; Abcam). Samples were derived from melanoma $(n=78)$, non-small cell lung cancer $(n=52)$, breast cancer $(n=25)$, renal cell cancer $(n=9)$, colon cancer $(n=9)$, small cell lung cancer $(n=7)$, carcinomas not otherwise specified $(n=9)$ and other rare cases like ovarian and esophageal cancer $(n=8)$. All staining procedures were performed using an automated immunostainer (Leica Bond III) and analyzed by $\geq$ two observers using a semi-quantitative score (H-Score) ranging from 0 to 300 . $\mathrm{H}$-Score is defined by the staining intensity ( 1 = weak, 2 = moderate, $3=$ strong) multiplied with the frequency of positive cells (\%).

\section{Statistics}

Statistical analyses were conducted with SPSS 21 for Mac (SPSS Inc.) and Prism 7 for Mac, Version 7.0b (La Jolla, CA, USA). An independent samples Student's $t$-test was used to compare two normally distributed groups. The Kruskal-Wallis test was used to analyze nonparametric data and Dunn's or Sidak's test was used to correct for multiple testing. Levene's test was used to assess the variance. Kaplan-Meier survival analysis and Mantel-Cox log-rank test were used to assess survival differences between groups. Values are presented as means \pm standard error of the mean (s.e.m.) unless otherwise specified. A two-tailed $P \leq 0.05$ was considered significant. 


\section{Study approval}

We obtained written informed consent before human tumor material was collected. The Regional Ethical Committee and the Norwegian Directorate of Health approved the collection and storage of human tissue. The Institutional Animal Care and Use Committee at the University of California Davis and at the University of Bergen approved the mouse experiments. At both institutions, mice were maintained in animal facilities certified by the Association for Assessment and Accreditation of Laboratory Animal Care International. The local ethical committee at the University Cancer Center Frankfurt approved the immunohistochemical analyses of human brain metastases.

\section{Results}

Predicting therapeutic compounds using inverse gene expression profiling

Using a highly characterized metastatic $B R A F$-mutant human melanoma xenograft model [57], we isolated and sorted tumor cells from brain, bone, adrenals and ovaries by flow cytometry (Fig. 1a, Additional file 2: Figure S2a, b). By comparing RNA-seq data from the different metastases, we identified a 108-gene brain metastasis signature using a comparative workflow of independent analyses of gene expression profiles from brain versus the other organ metastases (Fig. 1b, and Additional file 2: Figure S2c, d). The signature consisted of 54 upregulated and 54 downregulated genes (Additional file 2: Figure S2d). To identify therapeutic compounds with the potential to revert the gene signature, we queried cMap with the 108-gene brain metastasis signature. cMap revealed 1313 expression profiles, with a cMap score $<0$, which represent compounds with the potential to induce the opposite transcriptional response when compared with the signature (Additional file 2: Figure S2e). For further studies, we focused on the top 10 candidate compounds (all with cMap scores $<-0.90)$ as shown in Fig. 1c.

In vitro and in vivo drug screening reveals $\beta$-sitosterol as a potential therapeutic agent

The therapeutic efficacy of the compounds was assessed on four metastatic melanoma cell lines using monolayer viability and tumorsphere assays (Fig. 2a-c and Additional file 4: Figure S3). $\mathrm{IC}_{50}$ values were generally lower in tumorspheres than in monolayers. The most potent compounds for reducing viability were thiostrepton, memantine, and $\beta$-sitosterol (Fig. 2a, b). The $\mathrm{IC}_{50}$ values for normal human fibroblasts and astrocytes were $128.3 \mu \mathrm{M}$ and $1200.5 \mu \mathrm{M}$ respectively, whereas normal human melanocytes were not sensitive to $\beta$-sitosterol within the dose range studied (Additional file 4: Figure S3).
We next assessed the therapeutic efficacy of thiostrepton, memantine, and $\beta$-sitosterol using a highly standardized human-to-mouse brain metastasis model [57] (Fig. 3a). Quantitative analysis of baseline H1_DL2 melanoma cells (i.e. accumulation of tumor cells within the brain $24 \mathrm{~h}$ after injection) showed no significant differences between the treatment and vehicle (control) groups (Additional file 5: Figure S4a). Drug treatment was commenced one week after tumor cell injections. High-resolution magnetic resonance imaging (MRI) over the next $5-10$ weeks revealed a significant reduction in the number and volume of brain metastases in the $\beta$-sitosterol-treated mice when compared with vehicletreated mice (Fig. 3b, c and Additional file 5: Figure S4b). There were no differences in brain metastasis frequency or size between the vehicle and the thiostrepton or memantine groups (Student's $t$-test, $P \geq 0.05$ for all comparisons). BLI intensity was significantly lower for the $\beta$-sitosterol group when compared to the vehicle group at all time points, with the exception of brain BLI intensity at five weeks (Student's $t$-test, $P \geq 0.05$; Additional file 5: Figure S4c). Importantly, $\beta$-sitosteroltreated mice survived significantly longer than vehicletreated mice, whereas thiostrepton-treated mice had a significantly shorter lifespan. Also, memantine treatment did not affect survival (Fig. 3d).

\section{$\beta$-Sitosterol pre-treatment inhibits the formation of brain metastasis and increases animal survival}

To further validate the $\beta$-sitosterol treatment effect, we performed a new and more extensive in vivo study where $\beta$-sitosterol treatment started 1 week before tumor cell injection (Fig. 4a). MRI-based quantification of baseline H1_DL2 melanoma cells in mouse brains again showed an equal tumor cell exposure in the $\beta$-sitosterol and vehicle groups (Additional file 6: Figure S5a). Vehicletreated mice progressively lost weight from four weeks and onwards, whereas $\beta$-sitosterol-treated mice maintained a stable body weight (Additional file 6: Figure S5b). There were significantly fewer and smaller brain metastases in the $\beta$-sitosterol group than in the vehicle group (Fig. 4b, c and Additional file 6: Figure S5c). Brain BLI intensity was significantly lower in the $\beta$-sitosterol treatment group compared to the vehicle group at comparable time points (Fig. $4 \mathrm{~d}$ ). $\beta$-sitosterol treatment provided a significant survival benefit when compared with vehicle treatment (Fig. 4e). When the study was terminated at 100 days, three out of nine mice treated with $\beta$-sitosterol were healthy and tumor-free as evaluated by brain MRI and histology. To confirm that the effects observed were not associated with the model used, we performed the same study using another highly aggressive brain tropic cell line (PC14_PE6_Br2). Also here, a significant 
reduction in brain metastatic burden was seen leading to a significant improved survival (Additional file 7: Figure S6).

\section{$\beta$-Sitosterol targets mitochondrial respiration through complex I inhibition}

To obtain mechanistic insight into the therapeutic action of $\beta$-sitosterol, we first examined the biological processes and signaling pathways associated with our brain metastasis signature. Functional classification of the signature genes showed an association with human metabolic processes and a number of cancer-related signaling pathways (Additional file 8: Figure S7a, b). We next examined known and predicted protein interactions of $\beta$-sitosterol and found direct interactions with 12 proteins within two distinct clusters related to apoptosis and cholesterol homeostasis (Additional file 8: Figure S7c). These 12 proteins acted in conjunction and were significantly associated with several biological processes, particularly metabolism and cell division (Additional file 8: Figure S7d). In order to explore whether specific signal transduction pathways were affected through the treatment with $\beta$-sitosterol, we performed a phosphorylation screen in vitro, and found reduced phosphorylation levels of a large number of oncogenic kinases following $\beta$-sitosterol treatment (Additional file 9: Figure S8). These data connected major regulators of cell homeostasis to the therapeutic potential of $\beta$-sitosterol and suggested that $\beta$-sitosterol may interfere with basic cellular functions such as energy metabolism and apoptosis.

Previous studies have shown that metastatic cells adapt their energy production in order to thrive in the brain microenvironment by increasing their mitochondrial respiration. This process has been shown to be a key mediator of resistance to BRAFi [15, 16, 24, 63]. We therefore investigated, by bioinformatics analyses, proteinprotein and protein-DNA interactions between the 121 Gene Ontology-annotated genes implicated in oxidative phosphorylation and (a) our brain metastasis signature or (b) known $\beta$-sitosterol targets. These analyses revealed large interaction networks with centrally located signature genes (Additional file 10: Figure S9) and $\beta$-sitosterol targets (Additional file 11: Figure S10). These data indicate that the therapeutic effect of $\beta$-sitosterol is linked to mitochondrial interference. Thus, we measured mitochondrial respiration and glycolysis by extracellular flux analysis in H1_DL2 melanoma cells following $\beta$-sitosterol treatment. As shown in Fig. 5a, $\beta$-sitosterol strongly reduces basal mitochondrial respiration and respiratory capacity. The extracellular flux analysis further shows that inhibition of ATP synthase (with oligomycin) is similar in vehicleand $\beta$-sitosterol-treated cells (Fig. 5a), indicating that $\beta$-sitosterol does not disrupt the integrity of the mitochondrial inner membrane. Inhibition of respiratory CI revealed that most of the respiratory activity is linked to this complex (Fig. 5a) and importantly, suggested that CI was a likely $\beta$-sitosterol target. Basal glycolysis and glycolytic capacity were, however, unaffected by $\beta$-sitosterol (Fig. 5b). Interestingly, melanoma cells showed minimal glycolytic reserve (glycolytic capacity minus basal glycolysis) if mitochondrial ATP production should cease (Fig. 5b). Thus, the cells could be particularly sensitive to inhibitors of mitochondrial respiration such as $\beta$-sitosterol. For comparison, we also measured the respiratory capacity of normal melanocytes following $\beta$-sitosterol treatment. Compared to the tumor cells, no changes in respiratory capacity was observed (Additional file 12: Figure S11).

To determine if the inhibitory effect of $\beta$-sitosterol on mitochondrial respiration was directly linked to the activity of $\mathrm{CI}$ or CII, we analyzed oxygen consumption rates in permeabilized cells by high-resolution respirometry. The $\mathrm{CI}+\mathrm{CII}$-driven respiratory activity was inhibited immediately following $\beta$-sitosterol exposure (Fig. 5c). Addition of the $\mathrm{CI}$ inhibitor, rotenone, did not provide further inhibition, and the remaining CII-driven rate was similar in the presence of $\beta$-sitosterol or rotenone (Fig. 5c). In summary, $\beta$-sitosterol inhibits mitochondrial respiration in tumor cells by acting as a CI inhibitor. Such an inhibition was not seen in normal melanocytes.

\section{$\beta$-Sitosterol increases oxidative stress and induces apoptosis}

Beyond their function in ATP synthesis, mitochondria are major producers of ROS. CI respiratory capacity is of particular importance in this respect, -and inhibition of its activity often results in increased ROS production [36]. Consistent with previous studies [4, 50], we observed a significant increase in cellular ROS content following $\beta$-sitosterol treatment (Fig. 6a). Interestingly, recent observations have shown that oxidative stress inhibits metastatic melanoma cells in the blood and visceral organs in vivo [42]. Since increased ROS levels have been linked to apoptosis induction, we next performed apoptosis analyses. As shown in Fig. 6b, a significant induction of apoptosis was observed following $\beta$-sitosterol treatment. This is in line with previous studies showing that $\beta$-sitosterol can induce both mitochondrial- and death receptor-mediated apoptosis in cancer cells $[4,8,23$, $50,64,65,70]$. Additionally, immunoblots for apoptotic markers (Fig. 6c) confirmed our protein interaction analysis (Additional file 8: Figure S7c). In summary, respiratory capacity is inhibited following $\beta$-sitosterol treatment which leads to an induction of apoptosis. In this context, it should also be emphasized that apoptosis is a hallmark of MAPK-targeted therapies as well as mitochondrial inhibitors, including known inhibitors of CI-mediated respiration [24, 36, 68]. 


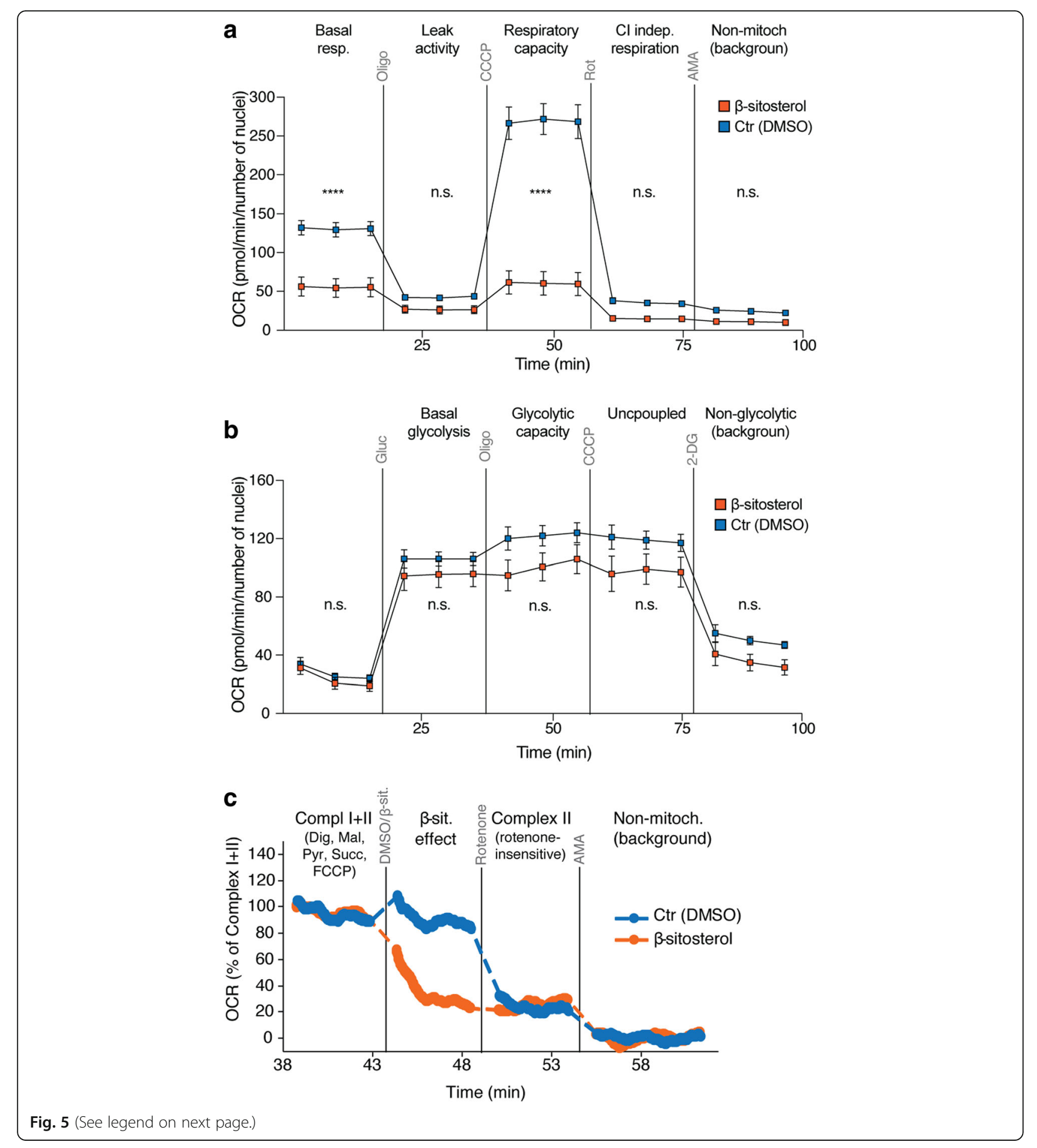

\section{$\beta$-Sitosterol abrogates potential resistance to BRAF inhibition}

Consistent with our previous observations that $\beta$-sitosterol inhibits mitochondrial respiration (Fig. 5a) and increases oxidative stress (Fig. 6a), we found a compensatory increase in $\mathrm{PGC} 1 \alpha$ expression with increasing concentrations of $\beta$-sitosterol (Fig. 7a). The MITF-PGC1 $\alpha$ axis is a master regulator of mitochondrial function in melanomas $[24,63]$. PGC1 $\alpha$ promotes mitochondrial respiration and protects against oxidative stress. A subset of melanomas overexpresses PGC1 $\alpha$, and treatment of $B R A F$-mutant melanomas with the BRAFi PLX4720 (a vemurafenib analogue) has been shown to upregulate PGC1 $\alpha$ [24, 63]. In agreement with these data, we 
(See figure on previous page.)

Fig. $5 \beta$-sitosterol reduces mitochondrial respiration through complex I inhibition. a-b Oxygen consumption rate (OCR) and extracellular acidification rate (ECAR) were measured to assess rates of mitochondrial respiration and glycolysis, respectively, in H1_DL2 cells treated with $50 \mu \mathrm{M} \beta$-sitosterol or $0.05 \%$ DMSO for $24 \mathrm{~h}$ (both: $\mathrm{n}=4$ ). a Basal respiration was determined, followed by sequential additions of oligomycin $(3 \mu \mathrm{M})$ to assess respiration due to proton leak, carbonyl cyanide 3-chlorophenylhydrazone (CCCP; $1.5 \mu \mathrm{M})$ to measure respiratory capacity, rotenone $(1 \mu \mathrm{M})$ to assess Complex I (CI) independent respiration and antimycin A (AMA; $1 \mu \mathrm{M}$ ) to determine background OCR. b Glucose $(10 \mathrm{mM})$ was provided to determine basal glycolysis, followed by sequential additions of oligomycin $(3 \mathrm{mM})$ to obtain glycolytic capacity, CCCP $(1.5 \mu \mathrm{M})$ to evaluate the influence of uncoupling and 2-deoxyglucose (2-DG; $100 \mathrm{mM})$ to measure the non-glycolytic background. $\mathbf{c}$ High-resolution respirometry in H1_DL2 cells to detect direct effects of $\beta$-sitosterol. First, the maximal $\mathrm{Cl}+\mathrm{Cll}$ driven respiratory capacity was measured in the presence of digitonin $(8.1 \mu \mathrm{M})$, malate $(2 \mathrm{mM})$, pyruvate $(1 \mathrm{mM})$, succinate $(10 \mathrm{mM})$ and carbonylcyanide-4-(trifluoromethoxy)-phenylhydraqone $(\mathrm{FCCP}, 0.18 \mu \mathrm{M})$. The respiratory rate was then measured after adding $\beta$-sitosterol $(50 \mu \mathrm{M})$ or DMSO $(0.05 \%)$, followed by rotenone $(0.5 \mu \mathrm{M})$ to inhibit $\mathrm{Cl}$, and $\mathrm{AMA}$ $(2.3 \mu \mathrm{M})$ to determine residual oxygen consumption. The experiment was repeated 3 times. a-c Student's $t$-test: $n$.s. $=$ not significant, $P \geq 0.05$, **** $P<0.0001$. Values are given as the mean \pm s.d

found that PLX4720 induced MitoTracker Red fluorescence, a measure of mitochondrial activity and mass (Fig. 7b). Importantly, these intrinsic and acquired survival advantages render melanoma cells resistant to BRAFi, and combined approaches that exploit the resultant dependence on mitochondrial respiration are highly sought $[24,45,49,63,69]$.

We therefore investigated the possible therapeutic benefits of combining BRAFi and mitochondrial CI inhibitors in colony formation assays. Both PLX4720 and $\beta$-sitosterol were effective as monotherapies, but regrowth of resistant clones appeared after long-term incubation (Fig. 7c). Combination treatment with PLX4720 and $\beta$-sitosterol, however, completely inhibited cell growth (Fig. 7c). To further substantiate the therapeutic potential of targeting mitochondrial CI (Fig. 5a, c), we constructed a stable NDUFA8 knockdown in the $\mathrm{H} 1$ melanoma cell line (H1_shNDUFA8) (Fig. 7d). NDUFA8 is an accessory subunit of mitochondrial $\mathrm{CI}$, in which knockdown results in failure of a functional complex and severe respiratory deficiency [55]. Long-term colony formation assays with PLX4720 alone or H1_shNDUFA8 alone displayed attenuated growth, whereas the combination totally eliminated cell growth (Fig. 7e). Next, we examined whether or not the combined effect was cell line specific. We performed monolayer viability assays in three other melanoma cell lines. Combination treatment with $\beta$-sitosterol and PLX4720 substantially reduced the $\mathrm{IC}_{50}$ values for all cell lines (Fig. 7f). As BRAFis in general have limited penetrability through an intact BBB [37] and the $\mathrm{BBB}$ is commonly not degraded in animal models until late in metastatic development [60], we carried out a proof of concept study in a subcutaneous Melmet 5 melanoma model. Both PLX4720 and $\beta$-sitosterol were effective as monotherapies, but combination treatment significantly reduced tumor growth (Fig. $7 \mathrm{~g}$ ).

To evaluate $\mathrm{CI}$ activity and the potential clinical relevance of our findings, we performed immunohistochemical staining of NDUFB8 (accessory subunit of CI) in 197 human brain metastases from various cancers.
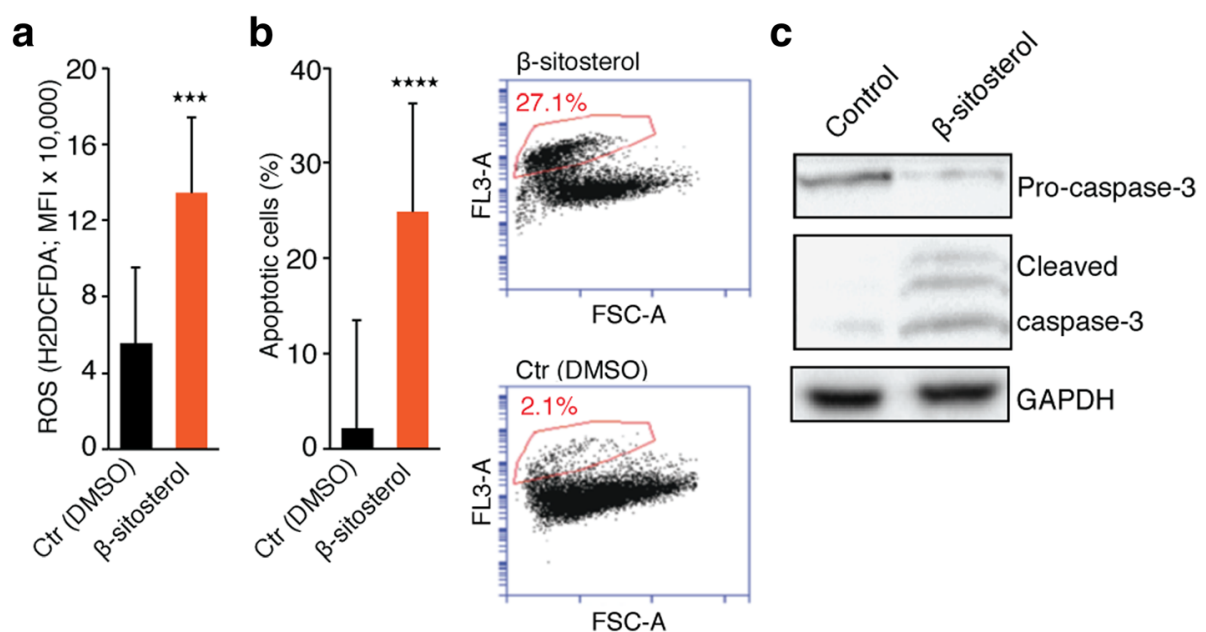

Fig. 6 -sitosterol increases ROS production and apoptosis. a ROS content (CM-H 2 DCFDA probe; mean fluorescence intensity (MFI); $n=2$ with triplicates). $\mathbf{b}$ Flow cytometric apoptosis assay $(n=3)$ showing a strong induction of apoptosis following $\beta$-sitosterol treatment. $\mathbf{c}$ Western blot of pro-caspase-3, cleaved caspase-3 and GAPDH in H1_DL2 cells exposed to DMSO (0.05\%) or $\beta$-sitosterol (50 $\mu \mathrm{M})$ for 2,24 or $24 \mathrm{~h}$, respectively. Student's t-test: ${ }^{* *} P<0.001,{ }^{* * *} P<0.0001$. Values are given as the mean \pm s.e.m 


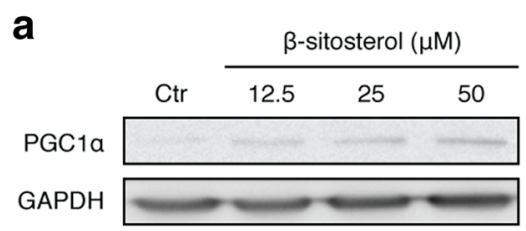

c

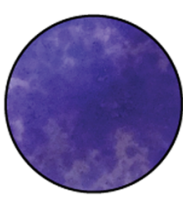

Control (DMSO)

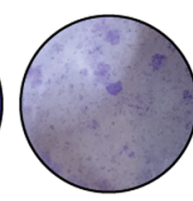

PLX4720

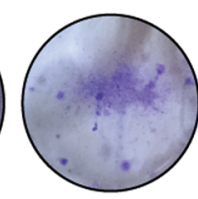

$\beta$-sitosterol

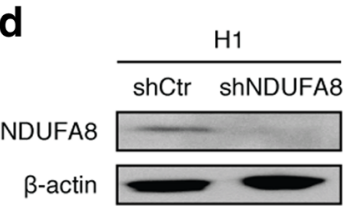

e

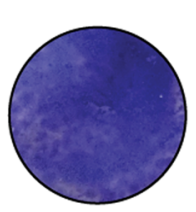

Control

(DMSO) b

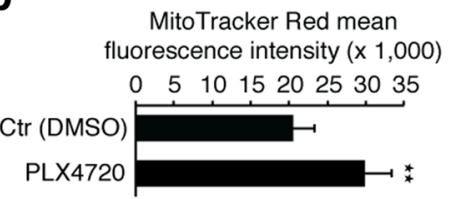

f

g

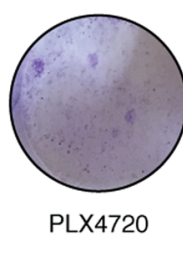

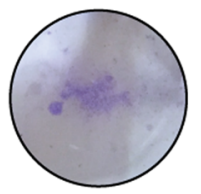

H1_shNDUFA8

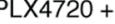
H1_shNDUFA8

\begin{tabular}{l|ccc}
$\mathrm{IC}_{50}(\mu \mathrm{M})$ & Melmet 1 & Melmet 5 & A375 \\
\hline$\beta$-sitosterol & 103.8 & 91.4 & 92.5 \\
PLX4720 & 10.9 & 23.9 & 5.9 \\
$\begin{array}{l}\beta \text {-sitosterol }+ \\
\text { PLX4720 }\end{array}$ & 1.6 & 4.6 & 0.3
\end{tabular}

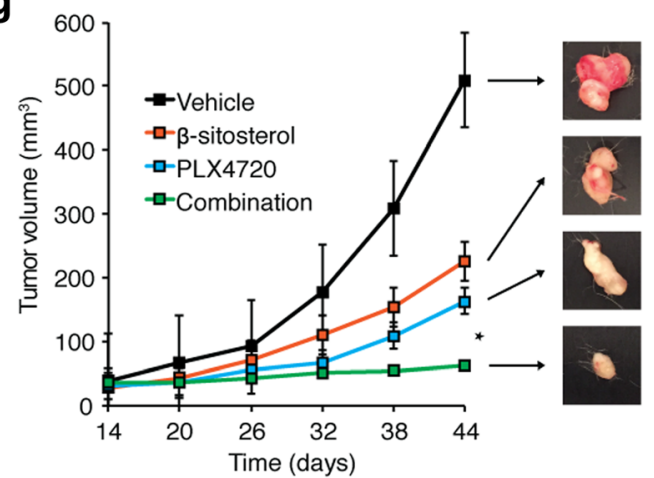

Fig. 7 Mitochondrial complex I inhibition prevents BRAFi resistance. a. Western blot of PGC1a and GAPDH in H1 cells treated with DMSO (0.05\%) or $\beta$-sitosterol $(12.5,25$ or $50 \mu \mathrm{M})$ for $24 \mathrm{~h}(\mathrm{n}=3)$. b. MitoTracker Red mean fluorescence intensity in $\mathrm{H} 1$ cells treated with DMSO $(0.05 \%)$ or vemurafenib $(1.5 \mu \mathrm{M})$ for $72 \mathrm{~h}(\mathrm{n}=3)$. c Colony formation assay (crystal violet staining) of $\mathrm{H} 1$ cells treated with DMSO $(0.05 \%)$ for 1 week, or vemurafenib $(1.5 \mu \mathrm{M})$, $\beta$-sitosterol $(50 \mu \mathrm{M})$, or vemurafenib $+\beta$-sitosterol for 3 weeks $(n=3)$. d Western blot of NDUFA8 and $\beta$-actin in H1_shCtr and H1_shNDUFA8 cells (NDUFA8 is required for assembly of a functional complex I). e Colony formation assay of $\mathrm{H} 1$ cells treated with DMSO $(0.05 \%)$ for one week or vemurafenib $(1.5 \mu \mathrm{M})$ for three weeks, and H1_shNDUFA8 cells alone or treated with vemurafenib $(1.5 \mu \mathrm{M})$ for three weeks $(n=3)$. $\mathbf{f}$ Half maximal inhibitory concentration $\left(I C_{50}\right)$ values for $\beta$-sitosterol, PLX4720 and the combination thereof in Melmet 1 , Melmet 5 and A375 cell lines $(n=3)$. g Subcutaneous tumor volume (width ${ }^{2} \times$ length)/2) in mice injected with $1 \times 10^{6}$ Melmet 5 cells. Mice were from two weeks onwards given daily i.p. injections of $0.1 \mathrm{~mL}$ vehicle (olive oil), $20 \mathrm{mg} / \mathrm{kg} \beta$-sitosterol in olive oil, $25 \mathrm{mg} / \mathrm{kg}$ PLX4720 in 0.05\% DMSO, or a combination of the two latter ( $n=8$ in each group). Representative images of tumors at 44 days are shown in the right panel. Student's $t$-test: * $P<0.05$. Values are given as the mean \pm s.e.m

Intriguingly, we found the highest expression levels for melanoma brain metastases (Additional file 13: Figure S12a, b). There was no difference in NDUFB8 expression between BRAF mutated and BRAF wild type melanoma brain metastases (Additional file 13: Figure S12c). Taken together, our data suggest that $\beta$-sitosterol prevents a key resistance mechanism to BRAFi therapy and may therefore be a beneficial therapeutic adjuvant in the treatment of melanoma brain metastasis.

\section{Discussion}

In this study, we used computational predictions based on gene expression analyses to identify potential drugs against BRAF-mutant melanoma brain metastases. The cholesterol analogue $\beta$-sitosterol was well tolerated, effectively reduced the number and volume of brain metastases, and improved survival in reproducible and predictive human-to-mouse brain metastasis models. As shown in Additional file 9: Figure S8, $\beta$-sitosterol may assert its function on many biological processes. From a 
therapeutic viewpoint, targeted therapies may have a limited effect, based on their complexity (heterogeneity and numerous cell signaling events occurring in melanomas). In the current work, we have shown that $\beta$-sitosterol has a particular effect on BRAF-driven tumors, but this does not exclude an action of $\beta$-sitosterol on other biological processes in tumor cells. For instance, the PC14_PE6_Br2 lung adenocarcinoma cell line, which is BRAF wild type, was also sensitive to $\beta$-sitosterol treatment, but to a lesser extent. We found in particular that the compound inhibited mitochondrial respiration through targeting of mitochondrial CI, which is a major facilitator of intrinsic and acquired resistance to MAPK-targeted therapies [24, 63]. Importantly, we also found that the combination of $\beta$-sitosterol and a BRAFi exhibited a strong therapeutic effect, compared to monotherapies.

Regarding a potential translational value of the presented findings, the preventive effect of $\beta$-sitosterol on the establishment of brain metastasis should be highlighted (Fig. 4). Since patients with melanomas and lung cancer show a significant propensity to develop brain metastasis during disease progression, $\beta$-sitosterol may, in a preventive setting, inhibit brain metastasis from the primary tumor.

To our knowledge, this is the first example of successful preclinical repurposing of a drug to treat melanoma-associated brain metastases. Repurposing of approved, non-anticancer drugs is an attractive drug discovery strategy in cancer with substantial advantages of cheaper, faster, and safer preclinical and clinical validation [11]. It should also be emphasized that high doses (3-4g) of $\beta$-sitosterol can be given daily to patients without side effects [30].

The phytosterol $\beta$-sitosterol is known as a competitive inhibitor of intestinal cholesterol uptake [30]. Phytosterols are generally classified as safe by the United States Food and Drug Administration, and the European Foods Safety Authority has concluded that a daily phytosterol and/or phytostanol intake of 1.5-2.4 g can reduce blood cholesterol by $7-10.5 \%$ and sustain this effect for up to 85 weeks [13]. Notably, we used a daily dose of $5 \mathrm{mg} / \mathrm{kg}$ in our experimental studies, which translates into 375 $\mathrm{mg}$ for a person weighing $75 \mathrm{~kg}$. Randomized controlled trials (RCTs) in humans have found beneficial effects of $\beta$-sitosterol (and its ester) on hypercholesterolemia, but also on benign prostatic hyperplasia, androgenic alopecia, and as an adjuvant in the treatment of tuberculosis, and anogenital warts $[9,20,35,43,53]$. No clinical trials have examined the effects of $\beta$-sitosterol on cancer. However, epidemiological studies have suggested that increased consumption of phytosterols can reduce the risk of different cancers [19, 33, 38, 61]. Data from cancer cell lines have shown that $\beta$-sitosterol can reduce cell proliferation and induce apoptosis in addition to inhibiting adhesion, invasion, and migration $[2,4-6,8$, $50,64,65,70]$. $\beta$-sitosterol has also been shown to inhibit the growth of tumor xenografts, reduce progression of carcinogen-induced tumors, and prevent metastatic lung and lymph node colonization [5, 8, 28, 29, 54]. The anticancer effects of $\beta$-sitosterol remain somewhat elusive, but a number of underlying mechanisms have been proposed [23]. As a potential therapeutic agent against brain metastases, it is particularly interesting that $\beta$-sitosterol has been shown to cross the BBB and accumulate in the brain $[25,62]$. With respect to our findings, it has previously been shown that $\beta$-sitosterol can incorporate into the inner mitochondrial membrane where it increases membrane fluidity [47]. It is also known that cancer cells may have an altered cholesterol loading, that may impair mitochondrial function leading to apoptosis protection [44]. Further studies on how $\beta$-sitosterol causes metabolic alterations in cancer cells are therefore warranted.

We found that, $\beta$-sitosterol displays broad-spectrum effects at both the genomic, proteomic, and metabolomic levels. Although extensive suppression of the MAPK pathway appears to be particularly important for metastatic melanoma, we also delineated a highly relevant mechanism of $\beta$-sitosterol, namely the reduction of mitochondrial respiration through $\mathrm{CI}$ inhibition with concurrent induction of ROS leading to apoptosis. This mitochondrial inhibition may have important ramifications for patients with metastatic melanoma, as increased mitochondrial oxidative capacity has been shown to mediate resistance to MAPK-targeted therapeutics and provide protection against oxidative damage and apoptosis [24, 63, 68]. Previous studies have indicated a therapeutic potential of various mitochondrial inhibitors and CI inhibitors in melanoma [21, 24, 36, 45, 49, 63, 68, 69]. In $B R A F$-mutant melanoma brain metastasis, we show that $\beta$-sitosterol efficiently prevented resistance to BRAFi therapy in vivo. Furthermore, largescale analyses of human brain metastases indicated a significant role of mitochondrial CI, which warrants further investigation. Intriguingly, emerging evidence suggests that mitochondrial respiration may be a particularly important survival mechanism and growth facilitator for metastatic cells in the brain microenvironment $[7,15,16,26]$.

\section{Conclusions}

In conclusion, we here leveraged robust in vivo model systems of brain metastasis to demonstrate the effects of $\beta$-sitosterol on BRAF-mutant melanoma [57]. Our study also indicates a therapeutic potential beyond brain metastasis that warrants further exploration in site-specific model systems. Importantly, to accomplish translational 
advances in brain metastasis research, there is a strong need for more preventive trials in selected high-risk patients or in patients with limited brain involvement [12]. Many metabolic modulators, including natural compounds and drugs used for conditions other than cancer, have favorable cost and toxicity profiles and might offer additional therapeutic benefit in metastatic melanoma. $\beta$-sitosterol can readily penetrate the $\mathrm{BBB}$ and has been studied in several randomized clinical trials of non-cancerous diseases [9, 20, 25, 35, 43, 53, 62]. Thus, our findings strongly encourage further assessment of $\beta$-sitosterol as an adjuvant to established MAPK-targeted therapies for patients with melanoma brain metastases or patients at risk of developing such metastases.

\section{Additional files}

Additional file 1: Figure S1. The diagram illustrates the step-by-step workflow and analysis strategy used in the current study. (TIF 1390 kb)

Additional file 2: Figure S2. Generation of organ samples for RNA sequencing, brain metastasis gene signature and Connectivity Map analysis. a BLI five weeks after intracardiac injection of $5 \times 10^{5} \mathrm{H} 1$ _DL2 cells in NOD.CB17-Prkdc scid $/ \mathrm{NcrCrl}$ mice $(n=7)$. M1-M7, indicate mouse 1 to 7. b Fluorescence-activated cell sorting (FACS) of GFP-positive tumor cells from the metastatic lesions. The sorted cells were analyzed by RNAseq $(n=7)$. c Heatmap of the 108-gene brain metastasis signature with organ samples in rows and genes in columns. $d$ The brain metastasis gene signature with the left two panels showing 54 upregulated genes in brain metastases and the right two panels showing 54 downregulated genes. e Query results from the Connectivity Map (cMap) database using the 108-gene signature. A score of $<0$ to -1 means net reversal of the signature (negative correlation) and a score of $>0$ to +1 means net induction of the signature (positive correlation). (TIF $2033 \mathrm{~kb}$ )

Additional file 3: Table S1. Tissue Digestion Protocols. Preparation of Liberase TM Research Grade (Roche Applied Science) working solution and organ-tailored protocols for tissue digestion (brain, adrenals, ovaries and bone). (DOCX $18 \mathrm{~kb})$

Additional file 4: Figure S3. Cell viability in vitro by increasing $\beta$ sitosterol concentrations. Human melanoma cell lines: a Melmet 1, b Melmet 5, and c A375 ( $n=18$ per cell line per drug per drug concentration). Normal cells: d SV-80 human lung fibroblasts $(n=18$ per drug concentration), e hTERT immortalized melanocytes and f Human astrocytes. All values are given as the mean \pm s.e.m. (TIF $943 \mathrm{~kb}$ )

Additional file 5: Figure S4. In vivo efficacy of candidate compounds on H1_DL2 brain metastases. a Left panel: Tumor cell load into the brain was quantified by MRI-based automated quantification of nanoparticlelabeled cells in NOD/SCID mouse brains $24 \mathrm{~h}$ after intracardiac injection of $5 \times 10^{5} \mathrm{H} 1$ _DL2 cells. Right panel: Images show typical MRI T2*weighted images of mouse brains (scale bar, $0.25 \mathrm{~cm}$ ) with an overlay of detected signals (blue). Study groups received $0.2 \mathrm{~mL}$ i.p. injections of 40 $\mathrm{mg} / \mathrm{kg}$ thiostrepton every second day $(n=5), 10 \mathrm{mg} / \mathrm{kg}$ memantine daily $(n=5), 5 \mathrm{mg} / \mathrm{kg} \beta$-sitosterol daily $(n=4)$ or vehicle (0.5\% DMSO; $n=5)$ from one week post-injection. See Fig. 3 for more details on this experiment. b Volume of brain metastases determined by MRI (T1weighted with contrast). Total volume of brain metastases per animal was compared at group level. c Brain BLI (total photon count = dorsal + ventral region of interest $(\mathrm{ROI})$. a-c Student's $t$-test: n.s. $P \geq 0.05$, * $P<0.05,{ }^{* *} P<0.01,{ }^{* * *} P<0.001$. All values are given as the mean \pm s.e.m. (TIF $3422 \mathrm{~kb}$ )

Additional file 6: Figure S5. In vivo validation of $\beta$-sitosterol on H1_DL2 brain metastasis. a Initial tumor cell load into the brain assessed by MRI-based automated quantification of nanoparticle-labeled cells $24 \mathrm{~h}$ after intracardiac injection of $5 \times 10^{5} \mathrm{H} 1$ _DL2 cells. Images show typical MRI T2*-weighted images of mouse brains (scale bar, $0.25 \mathrm{~cm}$ ) with an overlay of detected signals (blue). The study groups received daily i.p. injections of $0.1 \mathrm{~mL}$ vehicle (olive oil; $n=10$ ) or $\beta$-sitosterol $5 \mathrm{mg} / \mathrm{kg}$ diluted in olive oil $(n=9)$ starting one week before tumor cell injections. See Fig. 4 for more details on this experiment. b Body weight from week zero to eight. At 100 days, the three remaining $\beta$-sitosterol mice had an average body weight of $26.7 \pm 0.6 \mathrm{~g}$. c Volume of brain metastases assessed by MRI (T1-weighted with contrast). Total volumes of brain metastases per animal were compared at group level. a-c Student's $t$-test: n.s. $P \geq 0.05$, ${ }^{*} P<0.05$, ${ }^{* *} P<0.01,{ }^{* * *} P<0.001,{ }^{* * * *} P<0.0001$. All values are given as the mean \pm s.e.m. (TIF $726 \mathrm{~kb}$ )

Additional file 7: Figure S6. $\beta$-sitosterol treatment effect is not model specific. a Experiment overview. Mice were injected intracardially with $5 \times 10^{5}$ PC14_PE6_Br2 cells. Test groups received daily i.p. injections of $0.1 \mathrm{~mL}$ vehicle (olive oil; $n=4$ ) or $\beta$-sitosterol $5 \mathrm{mg} / \mathrm{kg}(n=6)$. Treatment started one week prior to tumor cell injections and was continued until euthanization. $b$ Body weight from week zero to four for vehicle and $\beta$ sitosterol-treated mice. c Number and d volume of brain metastases at MRI at three weeks (T1-weighted with contrast). Total volume of brain metastases per animal compared at group level. e Brain BLI at three weeks (total photon count $=$ dorsal + ventral region of interest). b-e Student's t-test: n.s. $P \geq 0.05,{ }^{*} P<0.05,{ }^{* *} P<0.01,{ }^{* * *} P<0.001$. $f$ Kaplan-Meier survival plot (Mantel-Cox log-rank test: ${ }^{* *} P<0.001$ ). All values are given as the mean \pm s.e.m. (TIFF $2165 \mathrm{~kb}$ )

Additional file 8: Figure S7. a Functional classification of the brain metastasis gene signature. Human biological processes (metabolic processes are highlighted in red), and b signaling pathways associated with the 108-gene brain metastasis signature using the Protein Analysis Through Evolutionary Relationships (PANTHER) classification system. C Known and predicted protein interactions of $\beta$-sitosterol from the Search Tool for Interactions of Chemicals (STITCH 4.0). Green lines represent direct interactions with $\beta$-sitosterol whereas blue lines represent proteinprotein interactions. Direct activation (green arrows) or inhibition (red lines) is indicated. d Significant statistical associations of $\beta$-sitosterol targets with cellular processes predicted with the Human Experimental/ Functional Mapper (HEFalMp). P-values represent approximate multiple hypothesis corrected values. (TIF $1333 \mathrm{~kb}$ )

Additional file 9: Figure S8. Protein phosphorylation screening following $\beta$-sitosterol treatment. Parallel determination of protein phosphorylation levels (43 oncogenic kinases and two total proteins) in H1_DL2 cells after $24 \mathrm{~h}$ treatment with vehicle (0.05\% DMSO) or $\beta$-sitosterol $(50 \mu \mathrm{M})$. (TIF $418 \mathrm{~kb})$

Additional file 10: Figure S9. Interaction network of signature genes and oxidative phosphorylation. The 121 Gene Ontology (GO)-annotated genes implicated in oxidative phosphorylation (red nodes) have 163 experimentally validated protein-protein and protein-DNA interactions involving 143 genes/proteins, including eight signature genes (green nodes). Purple nodes: Other genes that mediate interactions between signature and oxidative phosphorylation genes. Interaction directionality is represented with arrows. (TIF $1057 \mathrm{~kb}$ )

Additional file 11: Figure S10. Interaction network of $\beta$-sitosterol targets and oxidative phosphorylation. The 121 Gene Ontology (GO)-annotated genes implicated in oxidative phosphorylation (red nodes) have 155 experimentally validated protein-protein and protein-DNA interactions involving 141 genes/proteins, including four $\beta$-sitosterol targets (green nodes). Purple nodes: Other genes that mediate interactions between $\beta$-sitosterol targets and oxidative phosphorylation genes. Interaction directionality is represented with arrows. (TIF $1056 \mathrm{~kb}$ )

Additional file 12: Figure S11. The respiratory capacity (OCR) in norma melanocytes following $\beta$-sitosterol treatment as measured by the Seahorse system. Compared to the tumor cells (Fig. 5a) no changes in respiratory capacity was observed. (TIF $263 \mathrm{~kb}$ )

Additional file 13: Figure S12. Mitochondrial complex I activity in human brain metastases. a Expression levels of complex I subunit NDUFB8 in 197 human brain metastases from different cancers: Carcinoma not otherwise specified (NOS; $n=9)$, colon cancer $(n=9)$, breast cancer $(n=25)$, renal cell cancer (RCC; $n=9)$, non-small cell lung 
cancer (NSCLC: $n=52)$, small cell lung cancer (SCLC; $n=7)$, melanoma $(n=78)$ and others $(n=8) . H$-Score $=$ [staining intensity $(1=$ weak, $2=$ moderate, 3 = strong)] $\times$ [frequency of positive cells (\%)]. Kruskal-Wallis test with Dunn's multiple comparisons test: ${ }^{*} P<0.05$, ${ }^{* *} P<0.01$, ${ }^{* * * *} P<0.0001$ and for comparisons not indicated $P \geq 0.05$. b Immunohistochemistry of NDUFB8 in a human melanoma brain metastasis. c Expression levels of complex I subunit NDUFB8 in BRAF mutated melanoma (BRAFV600E; $n=24$ ) and BRAF wild type melanoma (no BRAFV600E; $n=23$ ). Kruskal-Wallis test with Dunn's multiple comparisons test: n.s.: not significant. (TIFF $12141 \mathrm{~kb}$ )

\section{Acknowledgments}

We thank Bridget McLaughlin (University of California Davis) for assistance with fluorescence-activated cell sorting. We thank Stephenie Y. Liu and Ryan R. Davis (UC Davis Comprehensive Cancer Center) for technical assistance with the RNA-Seq analysis. We thank Øystein Fodstad (University of Oslo) and Frank Winkler (University Hospital Heidelberg \& German Cancer Research Center, Heidelberg, Germany) for providing cell lines. We thank Petr Nazarov and Arnaud Muller (Luxembourg Institute of Health) and the BioStars community for helpful discussions on the bioinformatics. Imaging was performed at the Molecular Imaging Center (MIC), Department of Biomedicine, University of Bergen. We thank Hege A. Dale (MIC) for microscopy assistance, Tina Pavlin (MIC) for MRI technical assistance and Heidi Espedal (MIC) for valuable input on the cellular metabolism experiments. We thank Erlend Hodneland (University of Bergen) for quantifications of labeled tumor cells. We thank Knut Wester (University of Bergen) for manuscript proofreading. This work was supported by the Western Norway Regional Health Authority (911645, 911558 and 911990), Stiftelsen Kristian Gerhard Jebsen (2014-03), the University of Bergen (236608 and 710028), the Norwegian Cancer Society (182716), the Norwegian Research Council (214187 and 214381), the National Cancer Institute Cancer Center Support Grant P30 (P30 CA093373), the United States National Institutes of Health (R01HL124879 and R01CA134659) and the UC Davis RISE program.

\section{Availability of data and materials}

The raw sequence and processed expression data files are publicly available through NCBI GEO (http://www.ncbi.nlm.nih.gov/geo/) with accession number GSE100066.

\section{Authors' contributions}

$T S, L P, F A, K P, K W F, K J T, M L-L, R B$, and FT designed the study. TS, LP, FA, GVR, $J K V, S N A, M B, S B, Y B, K O S, E S I, L M M, S T, R \cup B, C G T$, and FT conducted the experiments. TS, LP, FA, GVR, MB, JKV, PH, KOS, CT, KP, KJT, RB, and FT analyzed the data. TS, RB, and FT wrote the manuscript. All authors contributed to and approved the final manuscript.

\section{Competing interests}

The authors declare that they have no competing interests.

\section{Publisher's Note}

Springer Nature remains neutral with regard to jurisdictional claims in published maps and institutional affiliations.

\section{Author details}

${ }^{1}$ Kristian Gerhard Jebsen Brain Tumour Research Centre, Department of Biomedicine, University of Bergen, Jonas Lies vei 91, 5009 Bergen, Norway. ${ }^{2}$ Department of Clinical Medicine, University of Bergen, Haukelandsveien 22 5021 Bergen, Norway. ${ }^{3}$ Department of Neurosurgery, Haukeland University Hospital, Haukelandsveien 22, 5021 Bergen, Norway. ${ }^{4}$ Department of Dermatology, Haukeland University Hospital, Haukelandsveien 22, 5021 Bergen, Norway. ${ }^{5}$ NorLux Neuro-Oncology Laboratory, Department of Oncology, Luxembourg Institute of Health, 84 Val Fleuri, 1526 Luxembourg, Luxembourg. ${ }^{6}$ Present address: Proteome and Genome Research Unit, Department of Oncology, Luxembourg Institute of Health, 1A-B, rue Thomas Edison, L-1445 Strassen, Luxembourg, Luxembourg. ${ }^{7}$ Department of Oncology and Medical Physics, Haukeland University Hospital, Haukelandsveien 22, 5021 Bergen, Norway. ${ }^{8}$ Department of Biomedicine, University of Bergen, Jonas Lies vei 91, 5009 Bergen, Norway.

${ }^{9}$ Edinger-Institute (Neurological Institute), Goethe-University Medical School, Heinrich-Hoffmann-Strasse 7, 60528 Frankfurt am Main, Germany. ${ }^{10}$ Institute of Marine Research, Nordnesgaten 50, 5005 Bergen, Norway. ${ }^{11}$ Department of Biomedical Engineering, University of California Davis, 451 East Health Sciences Drive, Davis, CA 95616, USA. ${ }^{12}$ Department of Biochemistry and Molecular Medicine, UC Davis Comprehensive Cancer Center, 4645 Second Avenue, Sacramento, CA 95817, USA. ${ }^{13}$ Computational Biology Unit, Department of Informatics, University of Bergen, Thormøhlensgate 55, 5008 Bergen, Norway. ${ }^{14}$ Institute of Pathology and Neuropathology, Department of Neuropathology, University of Tuebingen, Tuebingen, Germany. ${ }^{15}$ The Molecular Imaging Center, Department of Biomedicine, University of Bergen, Jonas Lies vei 91, 5009 Bergen, Norway.

Received: 7 March 2019 Accepted: 27 March 2019 Published online: 10 April 2019

\section{References}

1. Abildgaard C, Guldberg P (2015) Molecular drivers of cellular metabolic reprogramming in melanoma. Trends Mol Med 21:164-171. https://doi.org/ 10.1016/j.molmed.2014.12.007

2. Alvarez-Sala A, Attanzio A, Tesoriere L, Garcia-Llatas G, Barbera R, Cilla A (2018) Apoptotic effect of a phytosterol-ingredient and its main phytosterol (beta-sitosterol) in human cancer cell lines. Int J Food Sci Nutr:1-12. https:// doi.org/10.1080/09637486.2018.1511689

3. Arvold ND, Lee EQ, Mehta MP, Margolin K, Alexander BM, Lin NU et al (2016) Updates in the management of brain metastases. Neuro-Oncology 18:1043-1065. https://doi.org/10.1093/neuonc/now127

4. Awad AB, Burr AT, Fink CS (2005) Effect of resveratrol and beta-sitosterol in combination on reactive oxygen species and prostaglandin release by $\mathrm{PC}-3$ cells. Prostaglandins Leukot Essent Fatty Acids 72:219-226. https://doi.org/ 10.1016/j.plefa.2004.11.005

5. Awad AB, Fink CS, Williams $H$, Kim U (2001) In vitro and in vivo (SCID mice) effects of phytosterols on the growth and dissemination of human prostate cancer PC-3 cells. Eur J Cancer Prev 10:507-513

6. Awad AB, Williams H, Fink CS (2001) Phytosterols reduce in vitro metastatic ability of MDA-MB-231 human breast cancer cells. Nutr Cancer 40:157-164. https://doi.org/10.1207/S15327914NC402_12

7. Barbi de Moura M, Vincent G, Fayewicz SL, Bateman NW, Hood BL, Sun Met al (2012) Mitochondrial respiration--an important therapeutic target in melanoma. PLoS One 7: e40690 https://doi.org/10.1371/journal.pone. 0040690

8. Baskar AA, Ignacimuthu S, Paulraj GM, Al Numair KS (2010) Chemopreventive potential of beta-Sitosterol in experimental colon cancer model--an in vitro and in vivo study. BMC Complement Altern Med 10:24. https://doi.org/10.1186/1472-6882-10-24

9. Berges RR, Windeler J, Trampisch HJ, Senge T (1995) Randomised, placebo-controlled, double-blind clinical trial of beta-sitosterol in patients with benign prostatic hyperplasia. Beta-sitosterol Study Group. Lancet 345:1529-1532

10. Berghoff AS, Preusser M (2018) New developments in brain metastases. Ther Adv Neurol Disord 11:1-14. https://doi.org/10.1177/1756286418785502

11. Bertolini F, Sukhatme VP, Bouche G (2015) Drug repurposing in oncology-patient and health systems opportunities. Nat Rev Clin Oncol 12:732-742. https://doi.org/10.1038/nrclinonc.2015.169

12. Brabletz T, Lyden D, Steeg PS, Werb Z (2013) Roadblocks to translational advances on metastasis research. Nat Med 19:1104-1109. https://doi.org/10. 1038/nm.3327

13. Bresson J-L, Flynn A, Heinonen M, Hulshof $K$, Korhonen H, Lagiou P et al (2008) Plant Sterols and Blood Cholesterol - Scientific substantiation of a health claim related to plant sterols and lower/reduced blood cholesterol and reduced risk of (coronary) heart disease pursuant to Article 14 of Regulation (EC) No 1924/2006. The EFSA Journal 781:1-12. https://doi.org/ 10.2903/j.efsa.2008.781

14. Capper D, Berghoff AS, Magerle M, Ilhan A, Wohrer A, Hackl M et al (2012) Immunohistochemical testing of BRAF V600E status in 1,120 tumor tissue samples of patients with brain metastases. Acta Neuropathol 123:223-233. https://doi.org/10.1007/s00401-011-0887-y

15. Chen El, Hewel J, Krueger JS, Tiraby C, Weber MR, Kralli A et al (2007) Adaptation of energy metabolism in breast cancer brain metastases. Cancer Res 67:1472-1486. https://doi.org/10.1158/0008-5472.CAN-06-3137

16. Chen J, Lee HJ, Wu X, Huo L, Kim SJ, Xu L et al (2015) Gain of glucoseindependent growth upon metastasis of breast cancer cells to the brain. Cancer Res 75:554-565. https://doi.org/10.1158/0008-5472.CAN-14-2268 
17. Cohen JV, Tawbi H, Margolin KA, Amravadi R, Bosenberg M, Brastianos PK et al (2016) Melanoma central nervous system metastases: current approaches, challenges, and opportunities. Pigment Cell Melanoma Res 29:627-642. https://doi.org/10.1111/pcmr.12538

18. Davies MA, Saiag P, Robert C, Grob JJ, Flaherty KT, Arance A et al (2017) Dabrafenib plus trametinib in patients with BRAF(V600)-mutant melanoma brain metastases (COMBI-MB): a multicentre, multicohort, open-label, phase 2 trial. Lancet Oncol 18:863-873. https://doi.org/10.1016/S14702045(17)30429-1

19. De Stefani E, Boffetta P, Ronco AL, Brennan P, Deneo-Pellegrini H, Carzoglio JC et al (2000) Plant sterols and risk of stomach cancer: a case-control study in Uruguay. Nutr Cancer 37: 140-144 https://doi.org/10.1207/ S15327914NC372 4

20. Donald PR, Lamprecht JH, Freestone M, Albrecht CF, Bouic PJ, Kotze D et al (1997) A randomised placebo-controlled trial of the efficacy of betasitosterol and its glucoside as adjuvants in the treatment of pulmonary tuberculosis. Int J Tuberc Lung Dis 1:518-522

21. Fischer GM, Jalali A, Kircher DA, Lee WC, McQuade JL, Haydu LE et al (2019) Molecular profiling reveals unique immune and metabolic features of melanoma brain metastases. Cancer Discov. https://doi.org/10.1158/21598290.CD-18-1489

22. Gerstner ER, Fine RL (2007) Increased permeability of the blood-brain barrier to chemotherapy in metastatic brain tumors: establishing a treatment paradigm. J Clin Oncol 25:2306-2312. https://doi.org/10.1200/ JCO.2006.10.0677

23. Grattan BJ Jr (2013) Plant sterols as anticancer nutrients: evidence for their role in breast cancer. Nutrients 5:359-387. https://doi.org/10.3390/ nu5020359

24. Haq R, Shoag J, Andreu-Perez P, Yokoyama S, Edelman H, Rowe GC et al (2013) Oncogenic BRAF regulates oxidative metabolism via PGC1alpha and MITF. Cancer Cell 23:302-315. https://doi.org/10.1016/j.ccr.2013.02.003

25. Heverin M, Bogdanovic N, Lutjohann D, Bayer T, Pikuleva I, Bretillon L et al (2004) Changes in the levels of cerebral and extracerebral sterols in the brain of patients with Alzheimer's disease. J Lipid Res 45:186-193. https:// doi.org/10.1194/jlr.M300320-JLR200

26. Ho J, de Moura MB, Lin Y, Vincent G, Thorne S, Duncan LM et al (2012) Importance of glycolysis and oxidative phosphorylation in advanced melanoma. Mol Cancer 11:76. https://doi.org/10.1186/1476-4598-11-76

27. Ihan-Mutlu A, Osswald M, Liao Y, Gommel M, Reck M, Miles D et al (2016) Bevacizumab prevents brain metastases formation in lung adenocarcinoma. Mol Cancer Ther 15:702-710. https://doi.org/10.1158/ 1535-7163.MCT-15-0582

28. Imanaka H, Koide H, Shimizu K, Asai T, Kinouchi Shimizu N, Ishikado A et a (2008) Chemoprevention of tumor metastasis by liposomal beta-sitosterol intake. Biol Pharm Bull 31:400-404

29. Ju YH, Clausen LM, Allred KF, Almada AL, Helferich WG (2004) BetaSitosterol, beta-Sitosterol glucoside, and a mixture of beta-Sitosterol and beta-Sitosterol glucoside modulate the growth of estrogen-responsive breast Cancer cells in vitro and in Ovariectomized Athymic mice. J Nutr 134: 1145-1151. https://doi.org/10.1093/jn/134.5.1145

30. Law M (2000) Plant sterol and stanol margarines and health. BMJ 320:861-864

31. Lockman PR, Mittapalli RK, Taskar KS, Rudraraju V, Gril B, Bohn KA et al (2010) Heterogeneous blood-tumor barrier permeability determines drug efficacy in experimental brain metastases of breast cancer. Clin Cancer Res 16:5664-5678. https://doi.org/10.1158/1078-0432.CCR-10-1564

32. Long GV, Trefzer U, Davies MA, Kefford RF, Ascierto PA, Chapman PB et al (2012) Dabrafenib in patients with Val600Glu or Val600Lys BRAF-mutant melanoma metastatic to the brain (BREAK-MB): a multicentre, open-label, phase 2 trial. Lancet Oncol 13:1087-1095. https://doi.org/10.1016/S14702045(12)70431-X

33. Mendilaharsu M, De Stefani E, Deneo-Pellegrini H, Carzoglio J, Ronco A (1998) Phytosterols and risk of lung cancer: a case-control study in Uruguay. Lung Cancer 21:37-45

34. Meyer M, Essack M, Kanyanda S, Rees J (2008) A low-cost flow cytometric assay for the detection and quantification of apoptosis using an anionic halogenated fluorescein dye. Biotechniques 45:317-320. https://doi.org/10 2144/000112908

35. Miettinen TA, Puska P, Gylling H, Vanhanen H, Vartiainen E (1995) Reduction of serum cholesterol with sitostanol-ester margarine in a mildly hypercholesterolemic population. N Engl J Med 333:1308-1312. https://doi. org/10.1056/NEJM199511163332002
36. Miskimins WK, Ahn HJ, Kim JY, Ryu S, Jung YS, Choi JY (2014) Synergistic anti-cancer effect of phenformin and oxamate. PLoS One 9:e85576. https:// doi.org/10.1371/journal.pone.0085576

37. Mittapalli RK, Vaidhyanathan S, Dudek AZ, Elmquist WF (2013) Mechanisms limiting distribution of the threonine-protein kinase B-RaF(V600E) inhibitor dabrafenib to the brain: implications for the treatment of melanoma brain metastases. J Pharmacol Exp Ther 344:655-664. https://doi.org/10.1124/jpet. 112.201475

38. Nair PP, Turjman N, Kessie G, Calkins B, Goodman GT, Davidovitz H et al (1984) Diet, nutrition intake, and metabolism in populations at high and low risk for colon cancer. Dietary cholesterol, beta-sitosterol, and stigmasterol. Am J Clin Nutr 40:927-930. https://doi.org/10.1093/ ajen/40.4.927

39. Neman J, Termini J, Wilczynski S, Vaidehi N, Choy C, Kowolik CM et al (2014) Human breast cancer metastases to the brain display GABAergic properties in the neural niche. Proc Natl Acad Sci U S A 111:984-989. https://doi.org/ 10.1073/pnas.1322098111

40. Palorini R, Simonetto T, Cirulli C, Chiaradonna F (2013) Mitochondrial complex I inhibitors and forced oxidative phosphorylation synergize in inducing cancer cell death. Int J Cell Biol 2013:243876. https://doi.org/10. 1155/2013/243876

41. Park ES, Kim SJ, Kim SW, Yoon SL, Leem SH, Kim SB et al (2011) Crossspecies hybridization of microarrays for studying tumor transcriptome of brain metastasis. Proc Natl Acad Sci U S A 108:17456-17461. https://doi.org/ 10.1073/pnas.1114210108

42. Piskounova E, Agathocleous M, Murphy MM, Hu Z, Huddlestun SE, Zhao Z et al (2015) Oxidative stress inhibits distant metastasis by human melanoma cells. Nature 527:186-191. https://doi.org/10.1038/nature15726

43. Prager N, Bickett K, French N, Marcovici G (2002) A randomized, doubleblind, placebo-controlled trial to determine the effectiveness of botanically derived inhibitors of 5-alpha-reductase in the treatment of androgenetic alopecia. J Altern Complement Med 8:143-152. https://doi.org/10.1089/acm. 2002.8.143

44. Ribas V, Garcia-Ruiz C, Fernandez-Checa JC (2016) Mitochondria, cholesterol and cancer cell metabolism. Clin Transl Med 5:22. https://doi.org/10.1186/ s40169-016-0106-5

45. Roesch A, Vultur A, Bogeski I, Wang H, Zimmermann KM, Speicher D et al (2013) Overcoming intrinsic multidrug resistance in melanoma by blocking the mitochondrial respiratory chain of slow-cycling JARID1B(high) cells. Cancer Cell 23:811-825. https://doi.org/10.1016/j.ccr.2013.05.003

46. Seifert H, Hirata E, Gore M, Khabra K, Messiou C, Larkin J et al (2016) Extrinsic factors can mediate resistance to BRAF inhibition in central nervous system melanoma metastases. Pigment Cell Melanoma Res 29:92100. https://doi.org/10.1111/pcmr.12424

47. Shi C, Wu F, Xu J (2013) Incorporation of beta-sitosterol into mitochondria membrane enhances mitochondrial function by promoting inner mitochondrial membrane fluidity. J Bioenerg Biomembr 45:301-305. https:// doi.org/10.1007/s10863-012-9495-3

48. Singh M, Venugopal C, Tokar T, Brown KR, McFarlane N, Bakhshinyan D et al (2017) RNAi screen identifies essential regulators of human brain metastasisinitiating cells. Acta Neuropathol 134:923-940. https://doi.org/10.1007/ s00401-017-1757-z

49. Smith MP, Brunton $H$, Rowling EJ, Ferguson J, Arozarena I, Miskolczi Z et al (2016) Inhibiting drivers of non-mutational drug tolerance is a salvage strategy for targeted melanoma therapy. Cancer Cell 29:270-284. https://doi. org/10.1016/j.ccell.2016.02.003

50. Sook SH, Lee HJ, Kim JH, Sohn EJ, Jung JH, Kim B et al (2014) Reactive oxygen species-mediated activation of AMP-activated protein kinase and cJun N-terminal kinase plays a critical role in beta-sitosterol-induced apoptosis in multiple myeloma U266 cells. Phytother Res 28:387-394. https://doi.org/10.1002/ptr.4999

51. Spagnolo F, Picasso V, Lambertini M, Ottaviano V, Dozin B, Queirolo P (2016) Survival of patients with metastatic melanoma and brain metastases in the era of MAP-kinase inhibitors and immunologic checkpoint blockade antibodies: a systematic review. Cancer Treat Rev 45:38-45. https://doi.org/ 10.1016/j.ctrv.2016.03.003

52. Steeg PS, Camphausen KA, Smith QR (2011) Brain metastases as preventive and therapeutic targets. Nat Rev Cancer 11:352-363. https:// doi.org/10.1038/nrc3053

53. Stefanaki C, Fasoulaki X, Kouris A, Caroni C, Papagianaki K, Mavrogianni $P$ et al (2015) A randomized trial of efficacy of beta-sitosterol and its 
glucoside as adjuvant to cryotherapy in the treatment of anogenital warts. J Dermatolog Treat 26:139-142. https://doi.org/10.3109/09546634. 2014.925535

54. Stoner GD, Chen T, Kresty LA, Aziz RM, Reinemann T, Nines R (2006) Protection against esophageal cancer in rodents with lyophilized berries: potential mechanisms. Nutr Cancer 54:33-46. https://doi.org/10.1207/ s15327914nc5401_5

55. Stroud DA, Surgenor EE, Formosa LE, Reljic B, Frazier AE, Dibley MG et al (2016) Accessory subunits are integral for assembly and function of human mitochondrial complex I. Nature 538:123-126. https://doi.org/10. 1038/nature19754

56. Sullivan RJ, Flaherty KT (2015) New strategies in melanoma: entering the era of combinatorial therapy. Clin Cancer Res 21:2424-2435. https://doi.org/10. 1158/1078-0432.CCR-14-1650

57. Sundstrom T, Daphu I, Wendelbo I, Hodneland E, Lundervold A, Immervoll H et al (2013) Automated tracking of nanoparticle-labeled melanoma cells improves the predictive power of a brain metastasis model. Cancer Res 73:2445-2456. https://doi.org/10.1158/0008-5472.CAN-12-3514

58. Sundstrom T, Espedal H, Harter PN, Fasmer KE, Skaftnesmo KO, Horn S et al (2015) Melanoma brain metastasis is independent of lactate dehydrogenase a expression. Neuro-Oncology 17:1374-1385. https:/doi.org/10.1093/ neuonc/nov040

59. Taggart D, Andreou T, Scott KJ, Williams J, Rippaus N, Brownlie RJ et al (2018) Anti-PD-1/anti-CTLA-4 efficacy in melanoma brain metastases depends on extracranial disease and augmentation of CD8(+) T cell trafficking. Proc Natl Acad Sci U S A 115:E1540-E1549. https://doi.org/10 1073/pnas. 1714089115

60. Thorsen F, Fite B, Mahakian LM, Seo JW, Qin S, Harrison V et al (2013) Multimodal imaging enables early detection and characterization of changes in tumor permeability of brain metastases. J Control Release 172: 812-822. https://doi.org/10.1016/j.jconrel.2013.10.019

61. Torres-Sanchez L, Galvan-Portillo M, Wolff MS, Lopez-Carrillo L (2009) Dietary consumption of phytochemicals and breast cancer risk in Mexican women. Public Health Nutr 12:825-831. https://doi.org/10.1017/S136898000800325X

62. Vanmierlo T, Weingartner O, van der Pol S, Husche C, Kerksiek A, Friedrichs $S$ et al (2012) Dietary intake of plant sterols stably increases plant sterol levels in the murine brain. J Lipid Res 53:726-735. https:// doi.org/10.1194/jlr.M017244

63. Vazquez F, Lim JH, Chim H, Bhalla K, Girnun G, Pierce K et al (2013) PGC1alpha expression defines a subset of human melanoma tumors with increased mitochondrial capacity and resistance to oxidative stress. Cancer Cell 23:287-301. https://doi.org/10.1016/j.ccr.2012.11.020

64. von Holtz RL, Fink CS, Awad AB (1998) Beta-Sitosterol activates the sphingomyelin cycle and induces apoptosis in $\mathrm{LNCaP}$ human prostate cancer cells. Nutr Cancer 32:8-12. https://doi.org/10.1080/ 01635589809514709

65. Vundru SS, Kale RK, Singh RP (2013) Beta-Sitosterol induces G1 arrest and causes depolarization of mitochondrial membrane potential in breast carcinoma MDA-MB-231 cells. BMC complement Altern med 13: 280. https://doi.org/10.1186/1472-6882-13-280

66. Wager $T$, Villalobos A, Verhoest PR, Hou X, Shaffer CL (2011) Strategies to optimize the brain availability of central nervous system drug candidates. Expert Opin Drug Discov 6:371-381. https://doi.org/10.1517/ 17460441.2011.564158

67. Webster RM, Mentzer SE (2014) The malignant melanoma landscape. Nat Rev Drug Discov 13:491-492. https://doi.org/10.1038/nrd4326

68. Wheaton WW, Weinberg SE, Hamanaka RB, Soberanes S, Sullivan LB, Anso E et al (2014) Metformin inhibits mitochondrial complex I of cancer cells to reduce tumorigenesis. Elife 3:e02242. https://doi.org/10.7554/eLife.02242

69. Zhang G, Frederick DT, Wu L, Wei Z, Krepler C, Srinivasan S et al (2016) Targeting mitochondrial biogenesis to overcome drug resistance to MAPK inhibitors. J Clin Invest 126:1834-1856. https://doi.org/10.1172/JCl82661

70. Zhao Y, Chang SK, Qu G, Li T, Cui H (2009) Beta-sitosterol inhibits cell growth and induces apoptosis in SGC-7901 human stomach cancer cells. J Agric Food Chem 57:5211-5218. https://doi.org/10.1021/jf803878n

Ready to submit your research? Choose BMC and benefit from:

- fast, convenient online submission

- thorough peer review by experienced researchers in your field

- rapid publication on acceptance

- support for research data, including large and complex data types

- gold Open Access which fosters wider collaboration and increased citations

- maximum visibility for your research: over $100 \mathrm{M}$ website views per year

At BMC, research is always in progress.

Learn more biomedcentral.com/submissions 